\title{
Generation of a large peptide phage display library by self-ligation
}

of whole-plasmid PCR product

Xu-Dong Kong ${ }^{1}$, Vanessa Carle ${ }^{1}$, Cristina Díaz-Perlas ${ }^{1}$, Kaycie Butler ${ }^{1}$ and Christian Heinis $^{1, *}$

${ }^{1}$ Institute of Chemical Sciences and Engineering, Ecole Polytechnique Fédérale de Lausanne (EPFL), Lausanne, $\mathrm{CH}-1015$, Switzerland

*To whom correspondence should be addressed. Tel: +41 (0)21 69393 50; Fax: +41 (0)21 69398 95; E-mail: christian.heinis@epfl.ch 


\section{ABSTRACT}

The success of phage display, used for developing target-specific binders based on peptides and proteins, depends on the size and diversity of the library screened, but generating large libraries of phage-encoded polypeptides remains challenging. New peptide phage display libraries developed in the last years rarely contained more than one billion clones, which appears to have become the upper size limit for libraries generated with a reasonable effort. Here, we established a strategy based on whole-plasmid PCR and self-ligation to clone a library with more than $2 \times 10^{10}$ members. The enormous library size could be obtained through amplifying the entire vector DNA by PCR, which omitted the step of vector isolation from bacterial cells, and appending DNA coding for the peptide library via a PCR primer, which enabled efficient DNA circularization by end-ligation to facilitate the difficult step of vector-insertion of DNA fragments. Panning the peptide repertoires against a target yielded high-affinity ligands and validated the quality of the library and thus the new library cloning strategy. This simple and efficient strategy places larger libraries within reach for nonspecialist researchers to hopefully expand the possible targets of phage display applications. 


\section{INTRODUCTION}

Peptides and proteins have become important therapeutics, with many developed with the help of in vitro evolution methods such as phage display. ${ }^{1}$ Phage display is a powerful technique that allows for screening large libraries of these biomolecules for binding to targets of interest. ${ }^{1,2}$ Although the chances of isolating good binders increase with a greater number and diversity of library molecules that can be sampled, ${ }^{3}$ phage display library sizes and designs have stagnated in the past decade. Most phage display libraries used today contain between a million and a billion different polypeptides, and libraries over this size are generally prohibitively difficult to make due to technical hurdles, including the generation of large quantities of phage vector encoding the polypeptides and the transformation of the DNA into individual bacterial cells. Even for specialized laboratories and companies with longstanding experience in DNA library construction, cloning a phage display library comprising more than a billion different peptides is a major task that typically takes multiple weeks.

Alternative display methods such as ribosome display and mRNA display omit the step of transforming library DNA into cells and allow for screening larger libraries, but important applications such as chemical modification of phage-peptides in organic-aqueous solutions, ${ }^{4}$ or performing selections under stringent conditions such as high temperature or proteolytic pressure ${ }^{5,6}$ are not possible. The demand for new peptide phage display libraries is thus unbroken. Alone in the last year, several large libraries were reported including the most recent ones in which phages display linear $X_{12}$ peptides $(X=$ any random amino acid; library size: $1.2 \times 10^{8}$ clones), ${ }^{7} Y^{*} X_{6} \mathrm{C}$ cyclic peptides (library size: $10^{8}$ clones; $Y^{*}=$ unnatural amino acid), ${ }^{8}$ and $\mathrm{CX}_{6} \mathrm{~K}^{*}$ cyclic peptides (library size: $10^{9}$ clones; $\mathrm{K}^{*}=$ unnatural amino acid) ${ }^{9}$ From these libraries with sizes ranging from 100 to 1000 million clones, peptides with desired qualities were isolated, but it is likely that larger libraries would yield peptides with even better properties.

Current techniques used for cloning phage display libraries are diverse and can be broadly divided into two groups. The first one includes strategies based on cassette mutagenesis in which double-stranded library DNA is ligated into linearized plasmid. ${ }^{10}$ The second group are Kunkel mutagenesis-type approaches in which degenerated oligonucleotides are annealed to single-stranded DNA followed by the synthesis of a complementary strand. ${ }^{11-14}$ Strategies based on cassette mutagenesis are frequently used for cloning phage display libraries, 
though they have multiple technical challenges that need to be overcome to be efficient. A first difficulty is the production of sufficient vector that needs to be isolated from bacterial cells and linearized by restriction endonucleases. This process is often plagued by the presence of variable forms of plasmid DNA, such as supercoiled DNA, which is occasionally more difficult to linearize. This makes electrophoretically separating linearized phage vector DNA from some forms of non-cleaved circular plasmid difficult, leading to transformation of vector without library insert. A second difficulty is DNA insertion into a linearized vector, which can yield various side-products, such as self-ligated vector or multimeric products in which several copies of insert, vector, or both are ligated. The third major challenge is inserting the circular DNA into bacterial cells, which is a naturally inefficient step due to the low permeability of membranes for DNA. For transforming DNA into cells, the membrane needs to be disrupted transiently to allow DNA entry and then closed again to insure cell survival, which typically works for only a small fraction of cells subjected to this process. Our laboratory has been cloning phage display libraries for the last ten years, and most comprise between 10 million and a billion different peptides. Only one contains more than a billion members $\left(4 \times 10^{9}\right),{ }^{15}$ which was obtained by applying a large effort to isolate more than one milligram of vector DNA from large $E$. coli cultures, transforming the ligated vector into electrocompetent cells grown in multiple liters of culture, and performing a large number of electroporations.

We hypothesized that large peptide phage display libraries could be more easily generated through whole-plasmid PCR, single restriction enzyme digestion, and intramolecular selfligation. Whole-plasmid PCR was used by Parikh and Guengerich for cloning a library of randomly mutated cytochrome $\mathrm{P} 450^{16}$ and by Matsumura and Rowe for generating a library of randomly mutated beta-galactosidase. ${ }^{17}$ To our knowledge, whole-plasmid PCR has neither been applied for the generation of peptide libraries and nor for cloning phage display libraries. Intramolecular self-ligation of linearized vector was used by Scott and co-workers for generating the largest peptide phage display library reported so far (LX-6 library, $10^{10}$ transformants) but in their approach, single-stranded DNA was isolated from cells and filled by a Klenow fragment rather than amplified by whole-plasmid PCR. ${ }^{14}$ The approach that we propose newly would facilitate the procedure of phage vector preparation and yield circular DNA containing exactly one gene insert, thus a good quality library. 
Our strategy for generating large phage display libraries is based on the amplification of the entire DNA of the phage vector by PCR, wherein the DNA coding for the peptide library is appended to the vector DNA through one of the two DNA primers (Figure 1A). The primer introducing the peptide library (forward primer) would anneal with its constant region to the $\mathrm{N}$-terminal region of the plll protein gene to display the peptides as a plll fusion. The second primer (reverse primer) would anneal downstream of the plll leader sequence and thus just before the region where the forward primer anneals. The two primers would additionally append Sfil restriction sites for ligating the two ends of the PCR product in an intramolecular reaction after Sfil digestion (red dots in Figure 1A). The strategy differs to approaches such as Kunkel mutagenesis and QuickChange ${ }^{\mathrm{TM}}$ cloning in which the DNA polymerase is synthesizing the complementary strand of a vector only, but is not amplifying the entire plasmid DNA in repetitive PCR cycles to synthesize micrograms of library DNA. Overall, our new approach was surprisingly efficient and allowed us to generate a large library comprising more than 20 billion different peptides, all by applying a comparatively moderate effort. Panning the libraries against several targets revealed convergent peptide evolution and yielded nanomolar binders, both indications for a good library quality. 


\section{RESULTS AND DISCUSSION}

\section{Design of large libraries of cyclic peptides}

We applied our herein proposed cloning approach (Figure 1) to the generation of large and structurally diverse cyclic peptide libraries, chosen for their ability to bind targets with high affinity and selectivity and their relatively high stability. ${ }^{18}$ Normally, cyclic peptide phage display libraries are obtained by displaying linear peptides on the phage tip that are subsequently cyclized by either forming a disulfide bridge between cysteines in the peptides or by bridging amino acids through a reaction with chemical linkers. ${ }^{19}$ In a recent work, we generated bicyclic peptide libraries by chemically bridging two pairs of cysteines in phagedisplayed peptides to increase the overall skeletal diversity (Figure 2), and so we designed a library based on this technology. ${ }^{20}$ The connection of four cysteines in peptides allows for generating cyclic peptides with an enormously large skeletal diversity because the four cysteines can be placed in different positions which gives $3(n-4) ! / 2(n-6)$ ! different backbone structures in peptides with a length of $n$ amino acids (Figure 2). We applied the wholeplasmid PCR cloning approach for generating six sub-libraries of peptides with lengths of 9 , $10,11,12,13$, and 14 amino acids. The peptides of the form $X_{C X} C X_{m} C X_{n} C X$ all contained a random amino acid at both ends and four cysteines spaced by different numbers of random amino acids wherein $\mathrm{I}+\mathrm{m}+\mathrm{n}=3,4,5,6,7,8$. Connecting two pairs of cysteines in the six sub-libraries yields $30,45,63,84,108$, and 135 different backbone formats (Figure 2). For cloning the libraries, we used the phage vector fd-tet-PK15 (9,255 bp), ${ }^{21} 155$ forward primers that appended the peptide DNA to the N-terminal end of the plll gene as shown in Figure 1, and a reverse primer that annealed downstream of the leader sequence of pllI, leading to PCR amplification of the whole vector. In addition to the peptide sequences, the forward primers append a Sfil restriction site to the vector DNA, which is required for DNA circularization. The reverse primer anneals just before a Sfil site present in the leader sequence, yielding a PCR product with Sfil sites at both ends (Figure 1).

\section{Whole-plasmid PCR and self-ligation}

The PCR amplification of the large phage vector fd-tet-PK15, around $9.2 \mathrm{~kb}$, required an efficient DNA polymerase with a low mutation rate. We used Phusion DNA polymerase, which can amplify a $\mathrm{kb}$ in around 15-30 seconds and has a lower error rate than, for example, Taq polymerase (around 50-fold lower) or Pfu polymerase (around 8-fold lower). PCR amplification of vector fd-tet-PK15 with the primer pair XD9_1 and XD_reverse at an 
elongation time of $7 \mathrm{~min}$ yielded a product with the desired size (around $30 \mathrm{ng} / \mu \mathrm{l}$ reaction; Figure $3 A$ ). A slightly better yield was obtained when the amount of vector template was increased from 5 to $40 \mathrm{ng}$, and it could be further increased to around $50 \mathrm{ng} / \mu \mathrm{l}$ when the amount of Phusion DNA polymerase was doubled to 0.08 units/ $\mu \mathrm{l}$ (Figure 3A). We applied the optimized conditions to PCR-amplify the phage vector in separate $50 \mu$ reactions using the 155 degenerated primers (Table S1), which yielded around $1 \mu \mathrm{g}$ of linear vector DNA per reaction. We separated the DNA of the reactions by agarose gel electrophoresis (Figure 3B) and extracted DNA of the desired size from the gel. The DNA encoding peptides of identical length were pooled to generate the six sub-libraries XD9 to XD14. For each sub-library, between 9 and $17 \mu \mathrm{g}$ of purified DNA was obtained.

We next cyclized the linear DNA of the six sub-libraries by first generating complementary sticky ends using Sfil, DNA purification, and incubation at a concentration of around $50 \mathrm{ng} / \mu \mathrm{l}$ with T4 ligase for two hrs at $20^{\circ} \mathrm{C}$. Gel electrophoretic analysis of a sample taken from a ligation reaction showed two bands, both running slower than the linear PCR product (Figure 3C). It was likely that one of the two bands corresponded to the desired cyclic product. After inactivation of the ligase and purification, between 5 and $12 \mu \mathrm{g}$ of DNA remained of each library (Figure 3D). Electroporation of the six DNA pools into electrocompetent $E$. coli cells yielded peptide sub-libraries with sizes between $1 \times 10^{8}$ and $6.5 \times 10^{9}$ as determined based on the number of colonies formed after electrotransformation (Figure 3D). For comparison, the largest one of the six sub-libraries, XD11 (11-amino acid peptides) was slightly larger than the largest peptide phage display library that we had developed previously $(6 \times 6$ library, $4 \times 10^{9}$ peptides). After electroporation of DNA into E.coli cells, we allowed the cells to recover by incubation in media for one hour at $37^{\circ} \mathrm{C}$ before plating them on selective agar plates. During the incubation time, cells could potentially duplicate or produce new phage that infect additional bacteria, which could lead to an over-estimation of the library size. We assessed such potential effects and found that the number of colonies formed after one hour of incubation is around 2-fold higher than if cells are plated immediately (one minute after electroporation) (Figure S1). The moderate increase in the colony number is likely due to multiple effects such as the recovery of electroporated (and damaged) cells and cell division. Importantly, the relatively small increase ensured that we did not over-estimate the library size, or at maximum by a factor of two. 


\section{Quality of peptide libraries analyzed by NGS}

To test the quality of the library and determine the efficiency of the PCR, we analyzed phage DNA of the sub-library XD12, encoding peptides of 12 amino acids, by sequencing around 1.7 million random clones, and we analyzed the data using previously described MatLab scripts. ${ }^{22}$ Reads that showed low sequencing quality (5.2\%) or were lacking constant regions of the vector (8.9\%) were eliminated as described in the Methods section. Of the remaining 1.5 million sequences, 93.2\% encoded peptides of exactly 12 amino acids and thus the desired length, $1.5 \%$ encoded peptides shorter than 12 amino acids, and 5.3\% were longer. Many of the shorter or longer sequences contained frame shifts and were expected to not yield plll protein and phage. Of the group with longer sequences, nearly all encoded the peptide PK15, which was part of the phage vector fd-tet-PK15 that was used as the PCR template. The relatively low percentage of PK15 sequences further confirmed that the processes of plasmid PCR amplification and ligation were efficient. We did not make an effort to reduce the percentage of PK15 sequences as we did not expect a negative impact on the phage selections. However, in case this is desired, strategies may be applied to remove template vector, for example by digestion with $D p n l$.

Of the around 1.4 million sequences coding for 12 -amino-acid peptides, $97.7 \%$ were found only once, suggesting that the vast majority of the sequences in the library were different, as expected (Figure 4A). Of these sequences, 63\% coded for peptides that contained exactly four cysteines, which was lower than the statistically expected number $\left[(31 / 32)^{(12-4)}=78 \%\right]$, and most of the remaining ones contained one or several additional cysteines (Figure 4B). The introduction of additional cysteines may be prevented in future libraries by using primers synthesized with mixtures of trinucleotides that lack cysteine condons. ${ }^{23,24}$ An analysis of the 28 sub-pools of the 12-amino-acid peptide sub-library revealed that all of them were present and similarly represented (Figure 4C).

To analyze the nucleotide and amino acid distributions, we looked at one sample sub-pool in more detail, the one with the format "XCXXCXXCXXCX". To start, we analyzed the frequency of nucleotides A, T, C, G at each position in 10,000 randomly picked sequences (Figure 4D). The four cysteines and the random amino acid positions were confirmed to be encoded by TGT and NNK codons, respectively. The nucleotides at the "N" positions coded for A, T, C, and G with frequencies of $30.3 \%, 19.2 \%, 31.7 \%$, and $18.8 \%$. In position "K", T and $G$ were found with equal frequency $(52.7 \%, 47.3 \%)$. Translation of the 10,000 
sequences into peptides and analysis of the amino acids in the randomized positions showed that the frequencies of most amino acids fit well with the theoretical number expected for NNK encoding, with His, Lys, Pro, Thr showing a slightly higher frequency and Gly, Leu, Val, Trp showing a slightly lower frequency than statistically expected (Figure 4E). A comparison of the codons of these two groups of amino acids revealed that amino acids with a higher frequency were encoded by codons with $A$ or $C$ in the first two positions and the amino acids with lower frequency with $T$ or $G$, suggesting that the small imbalance of amino acid representation resulted from the small bias in the nucleotide ratio described above.

\section{Isolation of low- to sub-micromolar binders}

Finally, we tested whether target-specific cyclic peptides could be isolated from the six peptide phage display sub-libraries in affinity selections against the model target streptavidin. We pooled phage of the six sub-libraries, bi-cyclized the displayed peptides by disulfide bridge formation, and panned them in two consecutive rounds against magnetic streptavidin beads. The isolated peptides converged to four different consensus groups, one of them containing the known streptavidin-binding peptide motif His-Pro-Gln in one of the three cysteine-spaced segments, which indicated the isolation of target-specific peptides (Figure $5 A)$. In the three other consensus groups, the sequence similarities were distributed over multiple cysteine-spaced segments. We synthesized four of the peptides with an N-terminal fluorescein moiety, cyclized the peptides by disulfide formation, separated the three regioisomers by reversed phase HPLC (Figure 5B), and tested the binding by fluorescence polarization. As expected, only one of the three regioisomers of each peptide sequence bound to the target. For three of the four peptide sequences, binding affinities in the singledigit micromolar or even sub-micromolar affinity range were found ( $K_{d}=120 \mathrm{nM}$; Figure $5 \mathrm{C}$ ).

Recently, we also applied the large peptide phage display library for the in vitro evolution of double-bridged peptides, a format in which two pairs of cysteines in the peptides are bridged by chemical linkers. ${ }^{20}$ The linkers were introduced post-display by reacting the cysteines with bis-electrophile reagents. Parallel application of multiple structurally diverse chemical linkers increased the library size by approximately another factor of ten. Selections against various targets including coagulation factor $\mathrm{XI}$ and interleukin-23 receptor yielded nanomolar binders, which further confirmed the quality of the library. ${ }^{21}$ 


\section{Discussion}

Technical improvements for manipulating and handling DNA have enabled the generation of ever larger phage display libraries, but because reported library sizes have not increased in the last ten years, it seemed that an upper library size limit had been reached. The largest phage display peptide library that we had cloned with a large effort contains four billion different peptides, ${ }^{19}$ and the largest phage display peptide library that we found in literature, the LX-6 library, contains ten billion different peptides. ${ }^{14}$ Herein, we present a cloning strategy that shifts the upper limit for phage library generation and enabled us to clone a cyclic peptide library of more than 20 billion peptides. This new approach, based on robust experimental procedures, enables the construction of larger libraries with a smaller effort than typical for even much smaller libraries.

Key for the large improvement in library generation was the technically simple generation of vector DNA by PCR and the efficient way of inserting library DNA into the vector. Despite the relatively large size of our vector of around $9 \mathrm{~kb}$, large quantities of DNA could be easily generated, and the product was homogenous, which is in contrast to vector DNA prepared from cells. The vector DNA generation by PCR was clearly facilitated by the tremendous improvements in DNA polymerase engineering that allowed for the amplification of long DNA strands with high efficiency and fidelity. An efficient insertion of peptide-coding DNA into the vector was achieved by appending the DNA to the vector DNA in a whole-plasmid PCR through an overhang PCR. The circularization of this DNA is then highly robust, because the ends are simply joined "intramolecularly". We have further facilitated the ligation by appending sticky ends via a Sfil site.

Compared to classical cassette mutagenesis in which the vector and DNA need to be incubated at an optimal ratio and in which two ligation events are required, this approach provided three key advantages. First, the vector DNA is efficiently produced by PCR and thus does not need to be prepared from bacterial cells, and it does not need to be linearized by restriction enzymes - both steps that are not trivial as described in the introduction. Second, the self-ligation of a PCR-amplified vector is an intra-molecular reaction that is more efficient than the inter-molecular ligation of an insert (digested PCR product) and a linearized vector, as also described above. Third, through the strong amplification of the vector DNA by PCR, the template vector represents a minor species and most of the generated plasmid contains library DNA. This contrasts with cassette mutagenesis approaches in which vector 
DNA is often not linearized or self-ligated, which can lead to a substantial percentage of plasmid without insert in the library.

For comparison with previous library-generation techniques, the largest one of the six sublibraries we produced in this paper, XD11 (11-amino acid peptides) was slightly larger than the largest peptide phage display library that we had developed previously $(6 \times 6$ library, $4 \times 10^{9}$ peptides). This previously developed $6 \times 6$ library was generated by transforming larger quantities of ligated DNA (33 $\mu \mathrm{g}$ vector, $9 \mu \mathrm{g}$ insert) and by performing more electroporations (> 50 electroporations), ${ }^{19}$ and thus applying a much larger effort. In other words, the new strategy yielded larger libraries in a shorter time, despite the use of less material and a smaller effort. The six sub-libraries together contain more than $2 \times 10^{10}$ peptides, which is five times more than the $6 \times 6$ library. The effort for cloning the six sub-libraries together was less than half compared to the work we had invested for creating the above described $6 \times 6$ library, showing that it would be significantly less work to use this strategy to test greater numbers of library variations in the future, such as variations in backbones or ring sizes.

A risk of the whole-plasmid PCR cloning strategy was that mutations would be introduced that could lead to unforeseeable biases in the iteratively performed affinity selections. For example, it was reported that phage clones with mutations in the 5'-untranslated region of gene II were particularly enriched in selections with the NEB library Ph.D.-7, ${ }^{25,26}$ and such mutations could potentially be introduced in the whole-plasmid PCR. We were pleased to see that in control selections performed without target protein, the vast majority of sequencing runs showed different peptide sequences $(97.7 \%)$ and no dominant clones, suggesting that no phage clones with strong propagation advantages were created. Importantly, in affinity selections with the model target streptavidin, we enriched strong binders, which further confirms that the library generated by whole-plasmid PCR has a high diversity and is of good quality. More specifically, we found that families of peptides with similar sequences were enriched, including a peptide family with the His-Pro-Gln motif that is characteristic for streptavidin binders. ${ }^{27}$ The convergent evolution is indicative of a successful selection. Additionally, sampling the large combinatorial libraries identified two new consensus sequences for streptavidin. Finally, the successful isolation of high affinity double-bridged peptides against several other targets (nanomolar binding constants), including coagulation factor XI and interleukin-23 receptor, reported in a recent work ${ }^{21}$ confirmed the good quality of the library. 
By generating a library comprising more than 20 billion clones, we have come closer to the theoretically largest possible phage display library size. The applied commercial TG1 electrocompetent cells have a transformation efficiency of $4 \times 10^{10} \mathrm{cfu} / \mu \mathrm{g}$ of pUC19 vector if a small ratio of DNA:cells is used (10 pg pUC19/25 $\mu$ l cells). Herein, we reached $1.3 \times 10^{9}$ $\mathrm{cfu} / \mu \mathrm{g}$ of ligated vector for the largest one of the six sub-libraries (XD11, 11-amino acid peptides). This value is rather close to the pUC19 control, in particular when considering that we used a higher ratio of DNA:cells to economize on expenses for cells $(1,250,000 \mathrm{pg} / 25 \mu \mathrm{l}$ cells) and that we used a much larger vector (9.2 kb versus $2.7 \mathrm{~kb})$. It is tempting to speculate that even larger phage display libraries can be generated by using a smaller vector, such as a $4 \mathrm{~kb}$ phagemid, that would have higher yields in the whole-plasmid PCR and a higher transformation yield.

The whole-plasmid PCR library cloning method developed herein is particularly suited for generating peptide libraries, as the DNA coding for peptides can easily be appended to the vector DNA by overhang PCR. The method may be applied to generate any type of peptide format, ranging from linear peptides over cyclic peptides to bicyclic structures. In principle, the whole-plasmid PCR cloning strategy could be applied for the generation of antibody phage display libraries as well. In the case of antibodies, the DNA coding for the antibody repertoires may be generated in PCRs, and the PCR products used as 'long primers' for the whole-plasmid PCR. Overall, the ability to make larger phage display libraries with a smaller effort will allow for the expansion of bio-based therapeutics, as more compounds and more formats can be tested with an increasingly shorter time. 


\section{METHODS}

\section{Phage vector}

The phage vector fd-tet-PK15 ${ }^{21}$ was used as template for the whole-plasmid PCR. This vector is based on the vector fd-tet ${ }^{28}$ that contains the genome of wild-type $\mathrm{fd}$ and a segment of transposon Tn10 coding for tetracycline resistance. The vector fd-tet-PK15 additionally contains DNA coding for the 17-amino-acid peptide PK15 ${ }^{19}$ and a Gly-Ser-Gly linker inserted between the modified leader sequence (changed from ...PFYSHS in wild-type fd genome to ...PFYAAQPAMA; altered sequence is underlined) and the plll. The region of the DNA coding for the leader sequence, the peptide PK15, and the start of pllI is shown below together with the sequence of the encoded protein. The leader sequence is shown in italics, the peptide in bold, the Sfil restriction site is doubly underlined, and the annealing region of the primers are underlined.

DNA sequence:

GTGAAAAAATTATTATTCGCAATTCCTTTAGTTGTTCCTTTCTATGCGGCCCAGCCGGCC ATGGCAGCATGTAGCGATCGTTTTCGTAATTGTCCGGCAGATGAAGCACTGTGTGGTG GTTCTGGCGCTGAAACTGTTGAAAGTTGT

Protein sequence:

VKKLLFAIPLVVPFY $\underline{\underline{A A P A M A A C S D R F R N C P A D E A L C G G S G A E T V E S C ~}}$

\section{Degenerated DNA primers}

The 155 primers introducing the DNA sequences coding for the peptides in the wholeplasmid PCR were ordered from Marcrogen who synthesized them at a $0.05 \mu \mathrm{mol}$ scale and purified them by MOPC ${ }^{\mathrm{TM}}$ which provided a purity $>85 \%$. The primers are shown in the Supplementary Table S1. The reverse primer XD_reverse (5'GCTTCATCTGCCGGACAATTACG-3') was used for all PCRs.

\section{Whole-plasmid PCR}

The whole-plasmid PCRs were performed in 0.2-ml thin-wall tubes in a total volume of $50 \mu \mathrm{l}$, wherein the following reagents were added in the indicated sequence while the tube and 
reagents were kept on ice. Degenerated forward primer (200 nM, final conc.), XD_reverse primer (200 nM, final conc.), dNTP mix (200 $\mu$ M each, final conc.), $40 \mathrm{ng}$ of phage vector fdtet-PK15 as template, $10 \mu$ of $5 \times$ HF Phusion buffer. The solution was filled up to $48 \mu$ with $\mathrm{ddH}_{2} \mathrm{O}$. Four units $(2 \mu \mathrm{l})$ of Phusion polymerase (CAT\# M0530L, New England Biolabs) were added, and the reaction was mixed by pipetting and then immediately incubated in the thermocycler with the following program. An overview of the PCR reagents and their final concentrations is shown in Supplementary Table S2. The following program was used: initial denaturation of $2 \mathrm{~min}$ at $95^{\circ} \mathrm{C} ; 25$ cycles of $30 \mathrm{sec}$ at $95^{\circ} \mathrm{C}, 45 \mathrm{sec}$ at $55^{\circ} \mathrm{C}$, and $7 \mathrm{~min}$ at $72^{\circ} \mathrm{C}$; and final elongation for $7 \mathrm{~min}$ at $72^{\circ} \mathrm{C}$.

The PCR product was purified by electrophoresis on a $1 \%$ agarose gel (containing $0.005 \%$ $\mathrm{v} / \mathrm{v}$ of ethidium bromide, $1 \mathrm{mM}$ guanosine) in Tris-Acetic acid-EDTA (TAE) buffer. The guanosine was added to protect DNA against damage by UV light. ${ }^{29}$ The DNA of each PCR $(50 \mu \mathrm{l})$ was electrophoresed in separate agarose-gel slots 2-mm thick, 10-mm wide, and 8$\mathrm{mm}$ deep. The bands running at around $10 \mathrm{~kb}$ were quickly excised under UV light, and the gel slices from the same sub-library were mixed before extracting the DNA using a kit (QIAquick ${ }^{\circledR}$ Gel Extraction Kit, Qiagen). The DNA was eluted from the kit columns using 10 $\mathrm{mM}$ Tris- $\mathrm{HCl}$ buffer, $\mathrm{pH} 8.5$ (three times $20 \mu \mathrm{l}$ ). The following number of columns were used for each 50- $\mu$ I PCR: libraries XD9, XD10, XD11, XD12-one column; libraries XD13, XD14-one column for two or three $50-\mu$ PCRs.

\section{DNA-end digestion by Sfi}

The two ends of the whole-plasmid PCR product were digested with Sfil (CAT\# R0123S, New England Biolabs) as follows. In a $0.5-\mathrm{ml}$ tube, $10 \mu \mathrm{g}$ of the PCR product and $20 \mu \mathrm{l}$ of $10 \times$ Cutsmart $^{\circledR}$ buffer were pipetted and diluted by filling up to $198 \mu \mathrm{l}$ with $\mathrm{ddH}_{2} \mathrm{O}$. Sfil $(2 \mu \mathrm{l}$, 40 units) was added, the reaction was mixed well by pipetting and was incubated for $4 \mathrm{hrs}$ at $50^{\circ} \mathrm{C}$. The digested PCR product was purified with a DNA purification kit (QIAquick ${ }^{\circledR}$ Gel Extraction Kit, Qiagen). The DNA was eluted from the columns (2 columns for $10 \mu \mathrm{g}$ of DNA) with $10 \mathrm{mM}$ Tris- $\mathrm{HCl}$ buffer, $\mathrm{pH} 8.5$ (three times $20 \mu \mathrm{l}$ ). 


\section{PCR product cyclization by self-ligation}

For each library, around $10 \mu \mathrm{g}$ of Sfil-digested PCR product was mixed with $20 \mu \mathrm{l}$ of $10 \mathrm{x}$ ligation buffer containing ATP, and the reaction was diluted by filling up to $180 \mu$ with $\mathrm{dd}_{2} \mathrm{O}$. T4 ligase ( $20 \mu \mathrm{l}, 100$ Weiss units, Thermo Fisher) was added, the reaction was mixed by pipetting, and was incubated at $20^{\circ} \mathrm{C}$ for $2 \mathrm{hrs}$. The ligation reaction was analyzed by electrophoresis to confirm completion, which was assessed by the appearance of the band of linear PCR product. The ligation mixture was incubated at $70^{\circ} \mathrm{C}$ for $10 \mathrm{~min}$ to inactivate the ligase, and the ligated DNA was purified with the DNA purification kit. Before the elution of DNA, the column was washed two additional times with wash buffer (Buffer EB, QIAquick ${ }^{\circledR}$ Gel Extraction Kit, Qiagen) to thoroughly remove the salt. The DNA was eluted from the column with $\mathrm{ddH}_{2} \mathrm{O}$ (three times $20 \mu \mathrm{l}$ ).

\section{Electroporation of DNA into E. coli cells}

Purified DNA (around 5 to $12 \mu \mathrm{g}$ in $60 \mu \mathrm{l}$ ) was electroporated into $100 \mu \mathrm{l}$ of commercial electrocompetent E. coli TG1 cells (Lucigen) in four cuvettes (around $40 \mu \mathrm{l}$ DNA/cell mixture per cuvette) under the bacteria (E. coli) mode of electroporator (Bio-Rad MicroPulser ${ }^{\mathrm{TM}}$ ). After each electroporation, cells were re-suspended in pre-warmed $\left(37^{\circ} \mathrm{C}\right)$ recovery medium (Lucigen) and were incubated for $1 \mathrm{hr}$ at $37^{\circ} \mathrm{C}$ with shaking (200 rpm). The size of the library was determined by measuring the total volume of electroporated cells, taking an aliquot of $20 \mu \mathrm{l}$ and plating a series of 10 -fold dilutions on small $2 \times Y T /$ tetracycline $(10 \mu \mathrm{g} / \mathrm{ml})$ agar plates. The rest of cells were plated on ten large $2 \times Y T /$ tetracycline agar plates $(14 \mathrm{~cm}$ diameter) and incubated at $37^{\circ} \mathrm{C}$ overnight. The E. coli TG1 cells on the plates were recovered in around $50 \mathrm{ml}$ of $2 \times \mathrm{YT}$ medium containing $10 \%$ glycerol. Aliquots of one $\mathrm{ml}$ were stored at $-80^{\circ} \mathrm{C}$ as glycerol stocks. 


\section{ASSOCIATED CONTENT}

Supporting Information

Supplementary methods chapters: Influence of post-electroporation incubation time on number of transformed bacteria. Next-generation sequencing of peptide library. Analysis of next-generation sequencing data. Phage selection against streptavidin. Synthesis of peptides. Determination of binding affinity by fluorescence polarization.

Supplementary Tables: Supplementary Table 1: Sequences of degenerated DNA primers used for the whole-plasmid PCR. Supplementary Table 2: Whole-plasmid PCR reagents. Supplementary Table 3: Primers used for the second PCR in NGS.

\section{ACKNOWLEDGEMENT}

We gratefully thank B. Mangeat from Gene Expression Core Facility of EPFL for help and useful suggestions on next generation sequencing of phage display libraries.

\section{FUNDING}

This work was supported by the Swiss National Science Foundation (grants 157842 and 192368). 


\section{REFERENCES}

(1) Nixon, A. E.; Sexton, D. J.; Ladner, R. C. Drugs Derived from Phage Display from Candidate Identification to Clinical Practice. MAbs 2014, 6 (1), 73-85.

https://doi.org/10.4161/mabs.27240.

(2) Smith, G. Filamentous Fusion Phage: Novel Expression Vectors That Display Cloned Antigens on the Virion Surface. Science (80-. ). 1985, 228 (4705), 1315-1317. https://doi.org/10.1126/science.4001944.

(3) Lindner, T.; Kolmar, H.; Haberkorn, U.; Mier, W. DNA Libraries for the Construction of Phage Libraries: Statistical and Structural Requirements and Synthetic Methods. Molecules 2011, 16 (2), 1625-1641. https://doi.org/10.3390/molecules16021625.

(4) Deyle, K.; Kong, X.-D.; Heinis, C. Phage Selection of Cyclic Peptides for Application in Research and Drug Development. Acc. Chem. Res. 2017, 50 (8), 1866-1874. https://doi.org/10.1021/acs.accounts.7b00184.

(5) Kristensen, P.; Winter, G. Proteolytic Selection for Protein Folding Using Filamentous Bacteriophages. Fold. Des. 1998, 3 (5), 321-328. https://doi.org/10.1016/S13590278(98)00044-3.

(6) Sieber, V.; Plückthun, A.; Schmid, F. X. Selecting Proteins with Improved Stability by a Phage-Based Method. Nat. Biotechnol. 1998, 16 (10), 955-960. https://doi.org/10.1038/nbt1098-955.

(7) Kara, E.; Nielsen, N. V.; Eggertsdottir, B.; Thiede, B.; Kanse, S. M.; Løset, G. Å. Design and Characterization of a New PVII Combinatorial Phage Display Peptide Library for Protease Substrate Mining Using Factor VII Activating Protease (FSAP) as Model. ChemBioChem 2020, 21 (13), 1875-1884.

https://doi.org/10.1002/cbic.201900705.

(8) Owens, A. E.; Iannuzzelli, J. A.; Gu, Y.; Fasan, R. MOrPH-PhD: An Integrated Phage Display Platform for the Discovery of Functional Genetically Encoded Peptide Macrocycles. ACS Cent. Sci. 2020, 6 (3), 368-381. https://doi.org/10.1021/acscentsci.9b00927.

(9) Wang, X. S.; Chen, P. C.; Hampton, J. T.; Tharp, J. M.; Reed, C. A.; Das, S. K.; Wang, D.; Hayatshahi, H. S.; Shen, Y.; Liu, J.; et al. A Genetically Encoded,

Phage- Displayed Cyclic- Peptide Library. Angew. Chemie Int. Ed. 2019, 58 (44), 15904-15909. https://doi.org/10.1002/anie.201908713. 
(10) Noren, K. A.; Noren, C. J. Construction of High-Complexity Combinatorial Phage Display Peptide Libraries. Methods 2001, 23 (2), 169-178.

https://doi.org/10.1006/meth.2000.1118.

(11) Kunkel, T. A. Rapid and Efficient Site-Specific Mutagenesis without Phenotypic Selection. Proc. Natl. Acad. Sci. 1985, 82 (2), 488-492. https://doi.org/10.1073/pnas.82.2.488.

(12) Papworth C, Bauer J, Braman J, W. D. Site-Directed Mutagenesis in One Day with $>80 \%$ Efficiency. Strategies 1996, 9 (8), 3-3. https://doi.org/10.1080/08924562.1996.11000299.

(13) Huang, R.; Fang, P.; Kay, B. K. Improvements to the Kunkel Mutagenesis Protocol for Constructing Primary and Secondary Phage-Display Libraries. Methods 2012, 58 (1), 10-17. https://doi.org/10.1016/j.ymeth.2012.08.008.

(14) Bonnycastle, L. L. C.; Mehroke, J. S.; Rashed, M.; Gong, X.; Scott, J. K. Probing the Basis of Antibody Reactivity with a Panel of Constrained Peptide Libraries Displayed by Filamentous Phage. J. Mol. Biol. 1996, 258 (5), 747-762. https://doi.org/10.1006/jmbi.1996.0284.

(15) Rentero Rebollo, I.; Heinis, C. Phage Selection of Bicyclic Peptides. Methods 2013, 60 (1), 46-54. https://doi.org/10.1016/j.ymeth.2012.12.008.

(16) Parikh A, G. F. Random Mutagenesis by Whole-Plasmid PCR Amplification. Biotechniques 1998, 24 (3), 428-431. https://doi.org/DOI: 10.2144/98243st01.

(17) Matsumura, I.; Rowe, L. A. Whole Plasmid Mutagenic PCR for Directed Protein Evolution. Biomol. Eng. 2005, 22 (1-3), 73-79.

https://doi.org/10.1016/j.bioeng.2004.10.004.

(18) Zorzi, A.; Deyle, K.; Heinis, C. Cyclic Peptide Therapeutics: Past, Present and Future. Curr. Opin. Chem. Biol. 2017, 38, 24-29. https://doi.org/10.1016/j.cbpa.2017.02.006.

(19) Heinis, C.; Rutherford, T.; Freund, S.; Winter, G. Phage-Encoded Combinatorial Chemical Libraries Based on Bicyclic Peptides. Nat. Chem. Biol. 2009, 5 (7), 502-507. https://doi.org/10.1038/nchembio.184.

(20) Kale, S. S.; Villequey, C.; Kong, X. D.; Zorzi, A.; Deyle, K.; Heinis, C. Cyclization of Peptides with Two Chemical Bridges Affords Large Scaffold Diversities. Nat. Chem. 2018, 10 (7), 715-723. https://doi.org/10.1038/s41557-018-0042-7.

(21) Kong, X.-D.; Moriya, J.; Carle, V.; Pojer, F.; Abriata, L. A.; Deyle, K.; Heinis, C. De 
Novo Development of Proteolytically Resistant Therapeutic Peptides for Oral Administration. Nat. Biomed. Eng. 2020, 4 (5), 560-571.

https://doi.org/10.1038/s41551-020-0556-3.

(22) Rentero Rebollo, I.; Sabisz, M.; Baeriswyl, V.; Heinis, C. Identification of Target-

Binding Peptide Motifs by High-Throughput Sequencing of Phage-Selected Peptides.

Nucleic Acids Res. 2014, 42 (22), e169-e169. https://doi.org/10.1093/nar/gku940.

(23) Krumpe, L. R.; Schumacher, K. M.; McMahon, J. B.; Makowski, L.; Mori, T.

Trinucleotide Cassettes Increase Diversity of T7 Phage-Displayed Peptide Library.

BMC Biotechnol. 2007, 7(1), 65. https://doi.org/10.1186/1472-6750-7-65.

(24) He, B.; Tjhung, K. F.; Bennett, N. J.; Chou, Y.; Rau, A.; Huang, J.; Derda, R.

Compositional Bias in Naïve and Chemically-Modified Phage-Displayed Libraries

Uncovered by Paired-End Deep Sequencing. Sci. Rep. 2018, 8 (1), 1214.

https://doi.org/10.1038/s41598-018-19439-2.

(25) Brammer, L. A.; Bolduc, B.; Kass, J. L.; Felice, K. M.; Noren, C. J.; Hall, M. F. A Target-Unrelated Peptide in an M13 Phage Display Library Traced to an Advantageous Mutation in the Gene II Ribosome-Binding Site. Anal. Biochem. 2008, 373 (1), 88-98. https://doi.org/10.1016/j.ab.2007.10.015.

(26) Zygiel, E. M.; Noren, K. A.; Adamkiewicz, M. A.; Aprile, R. J.; Bowditch, H. K.; Carroll, C. L.; Cerezo, M. A. S.; Dagher, A. M.; Hebert, C. R.; Hebert, L. E.; et al. Various Mutations Compensate for a Deleterious LacZa Insert in the Replication Enhancer of M13 Bacteriophage. PLoS One 2017, 12 (4), e0176421.

https://doi.org/10.1371/journal.pone.0176421.

(27) Katz, B. A. Binding to Protein Targets of Peptidic Leads Discovered by Phage Display: Crystal Structures of Streptavidin-Bound Linear and Cyclic Peptide Ligands Containing the HPQ Sequence. Biochemistry 1995, 34 (47), 15421-15429. https://doi.org/10.1021/bi00047a005.

(28) Zacher, A. N.; Stock, C. A.; Golden, J. W.; Smith, G. P. A New Filamentous Phage Cloning Vector: Fd-Tet. Gene 1980, 9 (1-2), 127-140. https://doi.org/10.1016/03781119(80)90171-7.

(29) Gründemann, D.; Schömig, E. Protection of DNA during Preparative Agarose Gel Electrophoresis against Damage Induced by Ultraviolet Light. Biotechniques 1996, 21 (5), 898-903. https://doi.org/10.2144/96215rr02. 


\section{FIGURES}

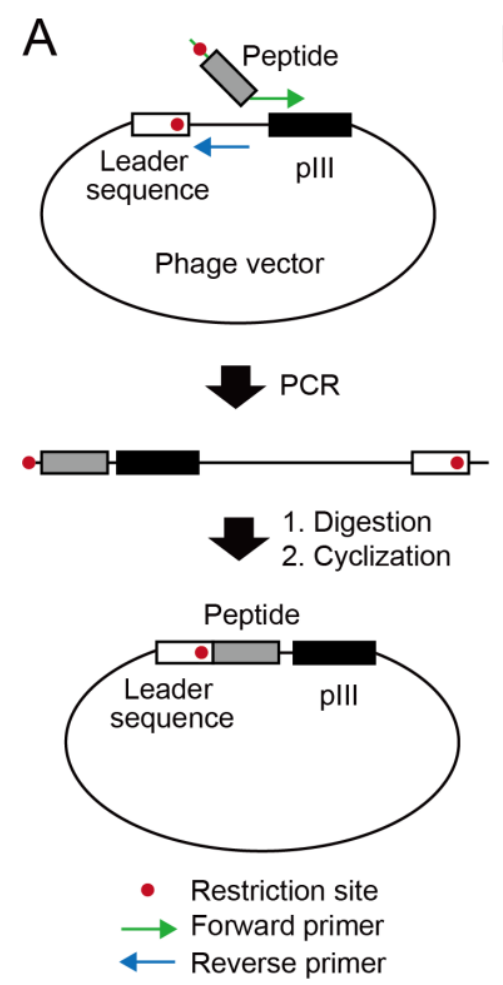

B

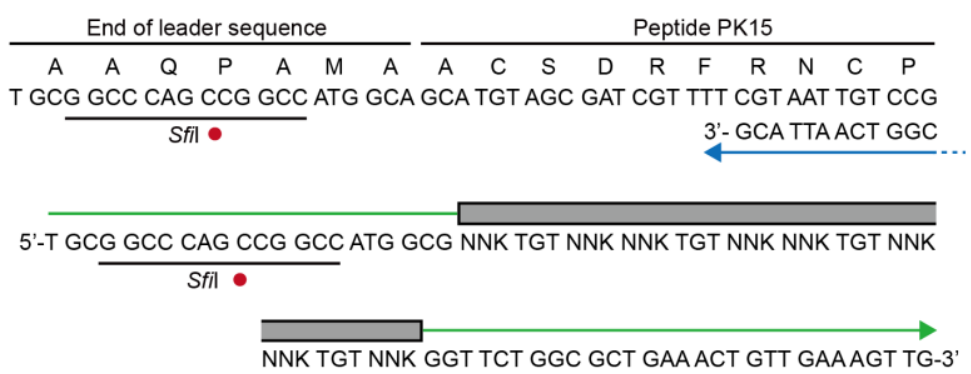

C

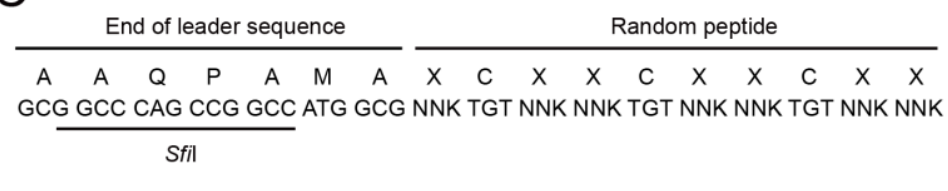

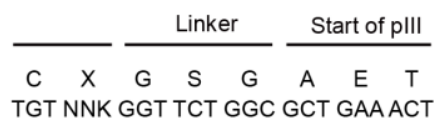

Figure 1. Whole-plasmid PCR phage display peptide library cloning strategy. (A) Experimental steps of cloning strategy. The forward primer anneals at the $\mathrm{N}$-terminus of the plll gene and appends a DNA sequence coding for a library peptide and a Sfil restriction site. The reverse primer anneals downstream of the leader sequence that contains a Sfil restriction site. The whole-plasmid PCR product contains a Sfil restriction site at each end, allowing for self-ligation after Sfil digestion. (B) Region of phage vector fd-tet-PK15 that encodes the $\mathrm{N}$-terminus of plll and the leader sequence. The sequences of the primers XD12_16 and XD_reverse and their annealing regions are shown. (C) Sequence of phage vector from a library sub-pool coding for 12-amino-acid peptides (library XD12). The regions showing the leader sequence, library peptide, and N-terminus of plll are shown. 


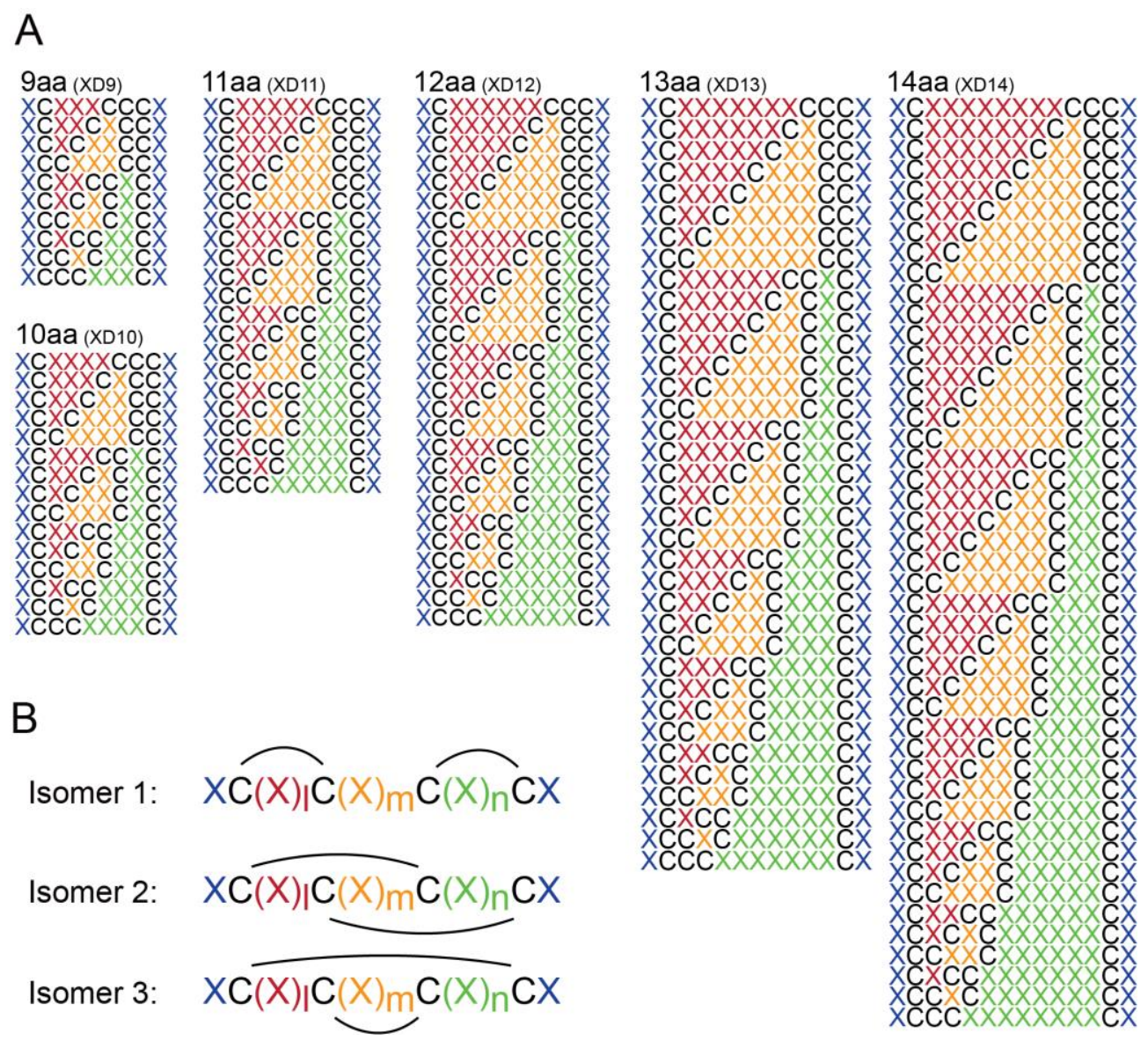

Figure 2. Peptide formats of the phage display library. (A) Positions of cysteines (C) and random amino acids $(X)$ are shown for the six phage display sub-libraries XD9 to XD14. The peptides have lengths between 9 and 14 amino acids and contain cysteines in four fixed positions. The libraries were cloned using 155 degenerate DNA primers (Supplementary Table S1) in which the random amino acids were encoded by NNK codons. The red, orange, and green colors show the three randomized segments. (B) The three peptide isomers that are formed upon oxidation of a 4-cysteine peptide. 

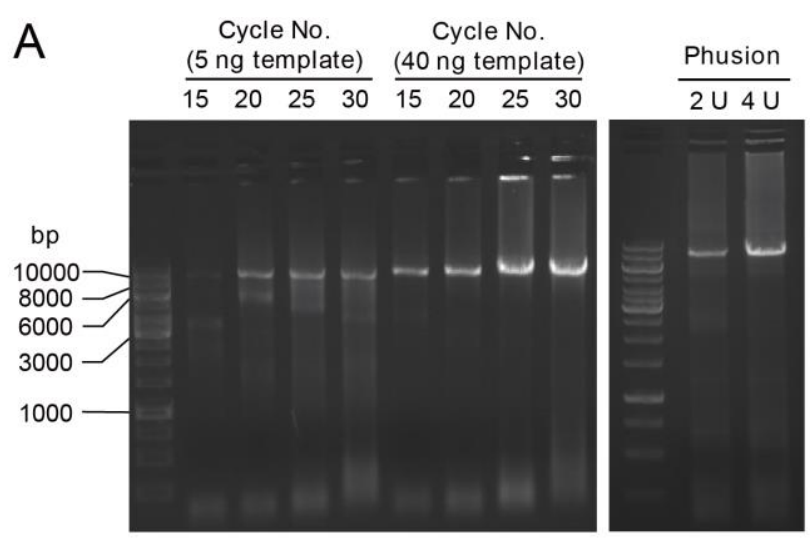

B
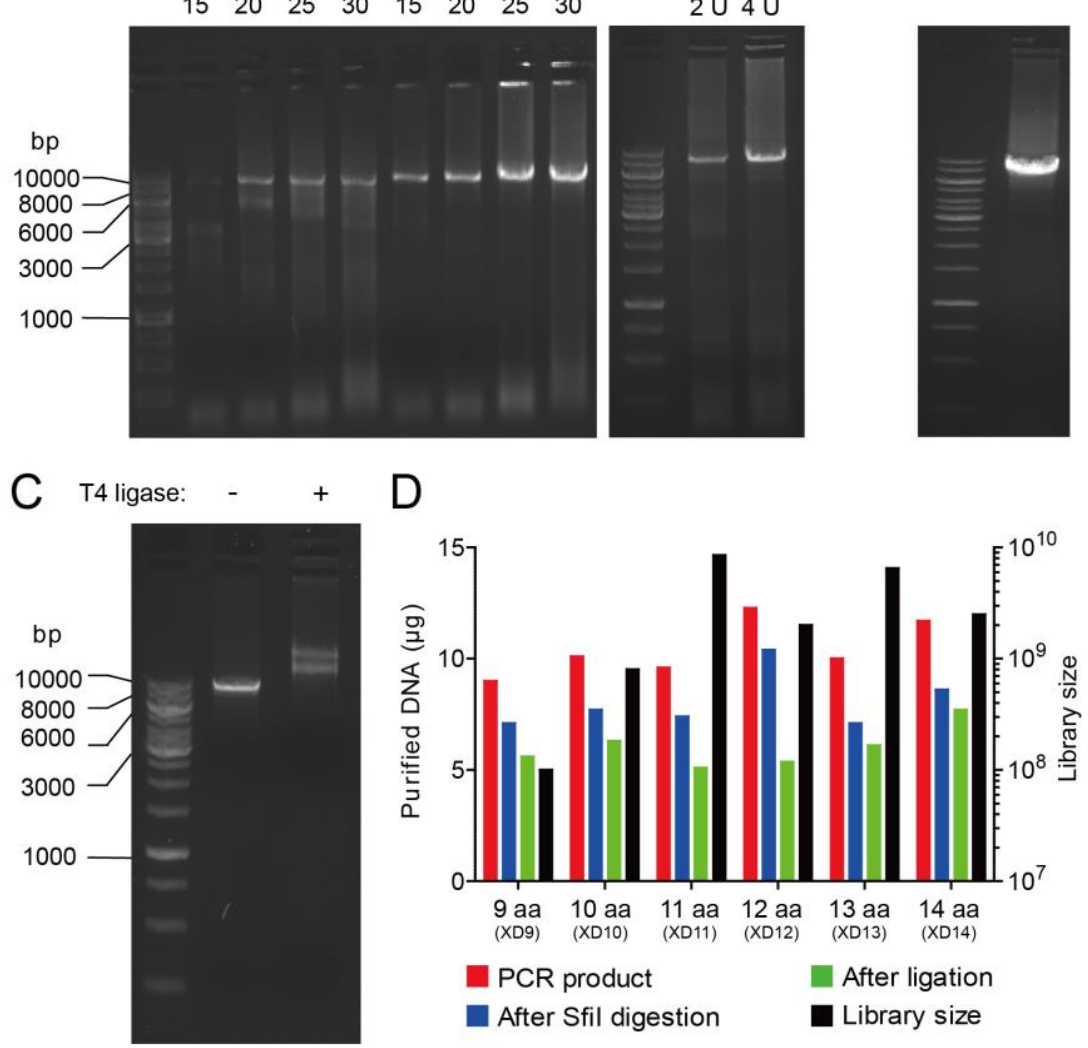

Figure 3. Peptide library cloning. (A) Optimization of whole-plasmid PCR by varying the quantity of template DNA, PCR cycle number, and quantity of Phusion polymerase, indicated for $50 \mu$ reactions. (B) Whole-plasmid PCR product using optimized conditions and a reaction volume of $50 \mu \mathrm{l}$. (C) Self-circularization of linear DNA by T4 ligase. (D) Quantity of DNA at each of three experimental steps (scale on left side, quantity of each library is indicated in $\mu \mathrm{g}$ of DNA) and the library size determined based on the number of colonies formed from diluted transformed $E$. coli cells (scale on right side). The quantity of DNA was determined after purification (gel extraction after PCR, PCR extraction kit after Sfil digestion, PCR extraction kit after ligation). 


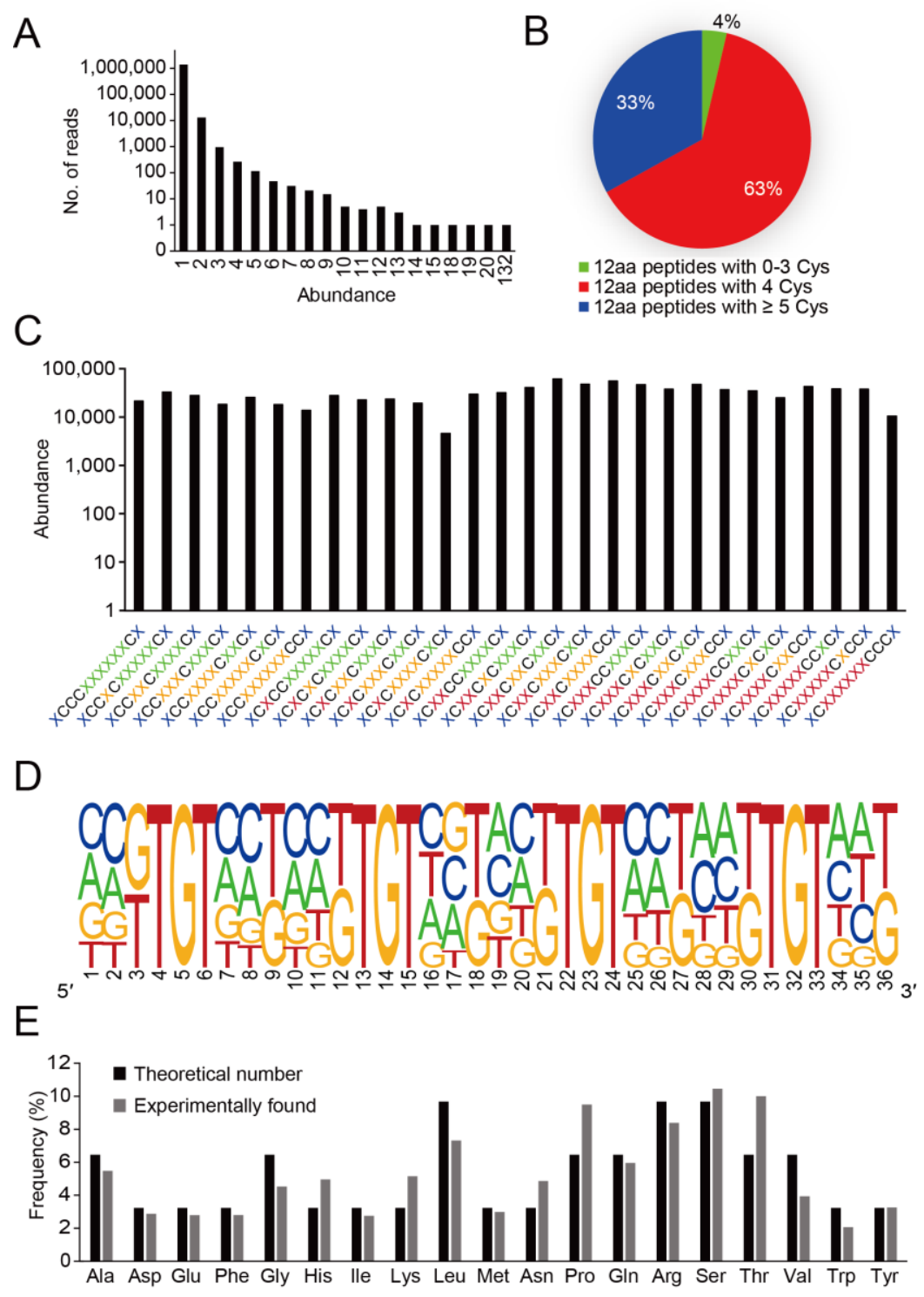

Figure 4. Quality of 12-amino-acid phage display peptide library (library XD12) analyzed by NGS. (A) Number of NGS reads ( $y$ ) for the indicated copy numbers ( $x$ ), analyzed for the 12amino acid peptide library. The vast majority of peptides were sequenced once. (B) Number of cysteines in peptides shown for the 12-amino-acid peptide sub-library. (C) Representation of the 28 pools of the 12-amino-acid peptide phage display sub-library. The number of NGS reads for each pool is indicated. (D) Frequency of nucleotides at each position of the pool coding peptides of the format XCXXCXXCXXCX. (E) Theoretical and experimental frequency of all amino acids (except cysteine) in the pool coding peptides of the format XCXXCXXCXXCX. 
A

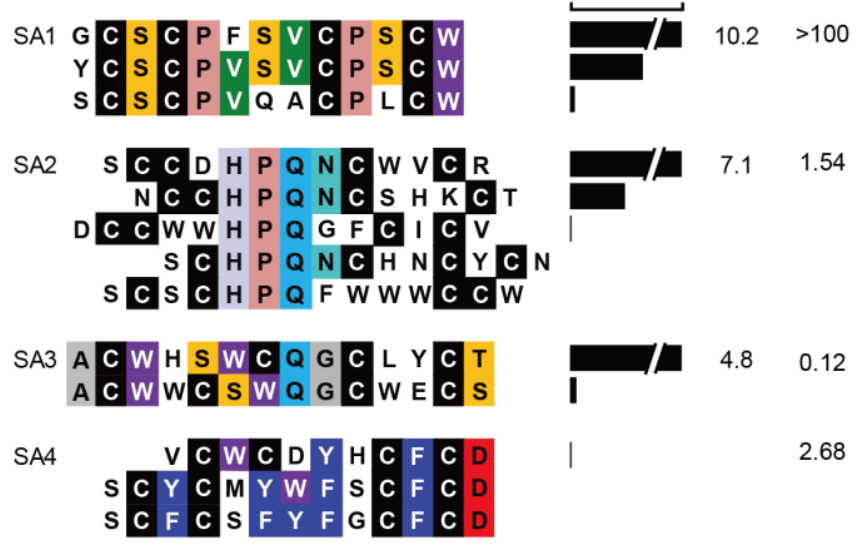

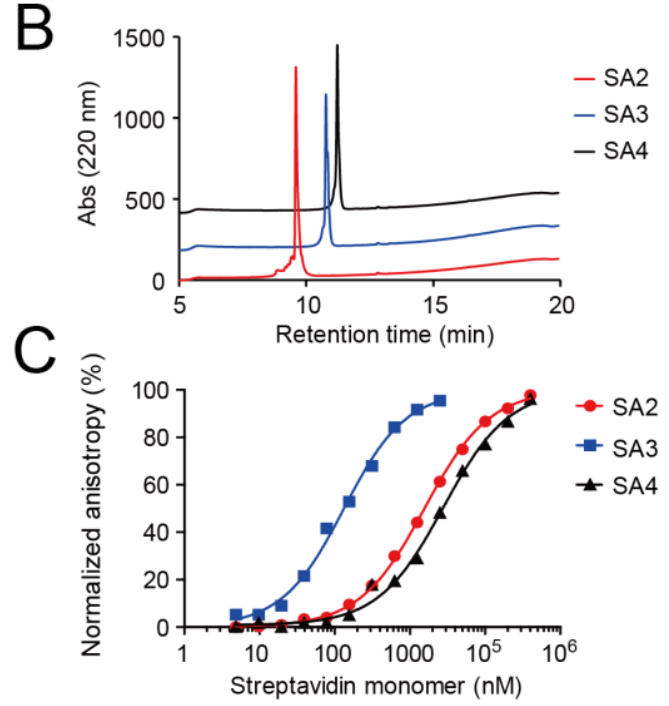

Figure 5. Phage display selections performed against streptavidin. (A) Alignment of peptides in groups based on sequence similarities. The abundance of the peptides is indicated. The binding affinity $\left(K_{\mathrm{d}}\right)$ of four peptides, labeled at the $\mathrm{N}$-terminus with fluorescein, was determined by fluorescence polarization. Mean values of two measurements are shown. (B) Analytical HPLC chromatograms of the active isomers of peptides SA2, SA3, and SA4. (C) Fluorescence polarization of peptides at increasing streptavidin concentrations. Mean values of two measurements are shown. 


\section{Generation of a large peptide phage display library by self-ligation of whole-plasmid PCR product}

Xu-Dong Kong ${ }^{1}$, Vanessa Carle ${ }^{1}$, Cristina Díaz-Perlas ${ }^{1}$, Kaycie Butler ${ }^{1}$ and Christian Heinis ${ }^{1, *}$

${ }^{1}$ Institute of Chemical Sciences and Engineering, Ecole Polytechnique Fédérale de Lausanne (EPFL), Lausanne, $\mathrm{CH}-1015$, Switzerland

*To whom correspondence should be addressed. Tel: +41 (0)21 69393 50; Fax: +41 (0)21 69398 95; E-mail: christian.heinis@epfl.ch 


\section{SUPPLEMENTARY METHODS}

Influence of post-electroporation incubation time on number of transformed bacteria

Phage vector fd-tet-PK15 (1.2 $\mu \mathrm{g}$ in $15 \mu \mathrm{l})$ was electroporated into $25 \mu \mathrm{l}$ of commercial electrocompetent $E$. coli TG1 cells (Lucigen) (around $40 \mu \mathrm{l}$ DNA/cell mixture per cuvette) under the bacteria (E. coli) mode of electroporator (Bio-Rad MicroPulser ${ }^{\mathrm{TM}}$ ). After the electroporation, cells were re-suspended in $1 \mathrm{ml}$ pre-warmed $\left(37^{\circ} \mathrm{C}\right)$ recovery medium (Lucigen) and were incubated for $4 \mathrm{hr}$ at $37^{\circ} \mathrm{C}$ with shaking (200 rpm). The number of cells containing a plasmid was determined by taking an aliquot of $20 \mu \mathrm{l}$ and plating a series of 10fold dilutions on small $2 \times Y T /$ tetracycline $(10 \mu \mathrm{g} / \mathrm{ml})$ agar plates. Samples were taken at the following time points: 1, 10, 20, 30, 40, 50, 60, 80, 100, 120, 150, 180, 210 and $240 \mathrm{~min}$. The protocol was repeated in independent three experiments.

\section{Next-generation sequencing of peptide library}

DNA from the glycerol stock of the phage peptide library XD12 was isolated using a commercial plasmid purification kit (Macherey-Nagel). DNA encoding the peptides in the plasmid was amplified by two consecutive PCRs. In the first reaction, an equimolar mixture of the five primers NGS_forward 1-5 was used as the forward primer and an equimolar mixture of the five primers NGS_reverse $1-5$ as the reverse primer.

NGS_forward 1-5:

5'-TCGTCGGCAGCGTCAGATGTGTATAAGAGACAG(N)。ATTCTATGCGGCCCAGC-3'

NGS_reverse 1-5:

5'-GTCTCGTGGGCTCGGAGATGTGTATAAGAGACAGG(N)_TTTCAGCGCCAGAACC-3'

$0=0$ to 4

The forward primer anneals at the end of the leader sequence and the reverse primer anneals in the region of the GSG-linker and the beginning of pllI. The PCR was prepared as follows. NGS_forward 1-5 (20 nM each, final conc.), NGS_reverse 1-5 (20 nM each, final conc.), dNTP mix (200 $\mu \mathrm{M}$ each, final conc.), $200 \mathrm{ng}$ of phage plasmid DNA as template, $5 \mu \mathrm{l}$ of $10 \times$ Taq buffer, and one unit $(0.2 \mu \mathrm{l})$ of Taq polymerase (New England Biolab) were used for a 50- $\mu$ PCR. The PCR mixture was immediately incubated in the thermocycler and the following program was used: initial denaturation of $2 \min$ at $95^{\circ} \mathrm{C} ; 20$ cycles of $30 \mathrm{~s}$ at $95^{\circ} \mathrm{C}$, $60 \mathrm{~s}$ at $55^{\circ} \mathrm{C}$, and $30 \mathrm{~s}$ at $68^{\circ} \mathrm{C}$; and final elongation for $5 \mathrm{~min}$ at $68^{\circ} \mathrm{C}$. The amplification 
efficiency was monitored on a $2 \%$ agarose gel (containing $0.005 \% \mathrm{v} / \mathrm{v}$ of ethidium bromide) with a band at around 150 to $200 \mathrm{bp}$.

In the second PCR, standard Illumina primers containing adapter and index sequences were used (Supplementary Table S3). The PCR was prepared as follows: NGS_PCR2_S508 (100 nM, final conc.), NGS_PCR2_N704 (100 nM each, final conc.), dNTP mix (200 $\mu \mathrm{M}$ each, final conc.), $2 \mu$ of reaction mixture of first PCR (directly used without purification), $5 \mu$ of $10 \times$ Taq buffer, and one unit $(0.2 \mu \mathrm{l})$ of Taq polymerase were used in $50 \mu \mathrm{l}$ of PCR. The PCR mixture was immediately incubated in the thermocycler with the same program as the first PCR. The PCR product was loaded on a $2 \%$ agarose gel (containing $0.005 \% \mathrm{v} / \mathrm{v}$ of ethidium bromide, $1 \mathrm{mM}$ guanosine) and the band with the size of around 200 to $250 \mathrm{bp}$ was gel extracted with a kit (Qiagen). The DNA was subsequently loaded at $1.5 \mathrm{pM}$ on a midoutput flow cell (Illumina) and sequenced on a NextSeq 500 instrument (Illumina) according to manufacturer instructions, yielding paired-end reads of 75 nucleotides. Overlapping paired-end reads were merged using CLC Genomics Workbench v9.5 (Qiagen). Of note, libraries were always sequenced along with at least $30 \%$ of unrelated non-amplicon-based libraries to avoid low-diversity problems. ${ }^{21,30}$

The sequencing data of the library XD12 (raw data and processed data) and of selections with streptavidin is provided on figshare (DOI: 10.6084/m9.figshare.12744716).

\section{Analysis of next-generation sequencing data}

Sequencing of the library XD12 by Illumina nextseq 500 yielded 1,760,658 DNA sequences. The data was processed and analyzed using MatLab scripts that we developed previously ${ }^{22}$ and as described in the following. In a first step, NGS reads with low sequencing quality were removed. An error filter of Q18_0 was applied to the sequencing dataset, which removed 92,093 sequences $(5.2 \%$ of $1,760,658)$ containing $>0$ low-quality nucleotides with $\mathrm{Q}$-score $\leq 18$ from the datasets. In a second step, sequences with incorrect start or end of the peptide region were removed. In total, $1,513,202(85.9 \%$ of $1,760,658)$ sequences contained a correct start and end (ATGGC and GGTTCT, encoding for Met-Ala and Gly-Ser respectively). These sequences of library peptide were extracted and translated into amino acid sequences of peptides. 
The peptide sequences were grouped according to the peptide length, wherein 22,922 peptide sequences $(1.5 \%$ of $1,513,202)$ were shorter than 12 amino acids. These peptides were comprised of i) sequences of peptides shorter than the 12-mer peptide in the library $X D 12$, ii) sequences from other sequencing samples of NGS that were assigned wrongly based on the index region, and iii) peptide sequences that contained GGTTCT (encoding Gly-Ser) and wrongly analyzed by the software (the software identifies the end of the peptides by the sequence Gly-Ser which is part of the linker Gly-Ser-Gly that connects the peptide and plII). The peptide with the highest abundance among the "short peptides" was found 53 times. Only 13 "short peptides" were found more than five times. The peptides longer than 12 amino acids (in total $80,499,5.3 \%$ of $1,513,202$ ) were mainly comprised of peptide PK15 (57,015 times) and variants of PK15 that appeared different due to sequencing errors. The PK15 contamination resulted from incomplete removal of fd-tet-PK15 used as PCR template. The sequences coding for peptides being shorter or longer than 12 amino acids, and not PK15, were most likely derived from erroneous DNA primers.

The MatLab script looplength. $m^{22}$ was used to analyze the number and positions of cysteines in the 12-mer peptides. The peptide sequences with the format XCXXCXXCXXCX, one of the 28 sub-libraries from the 12-mer library XD12, were analyzed at the DNA level. Ten thousand DNA sequences were chosen randomly using Microsoft Excel, and the frequency of nucleotides A, T, C, G at each position was analyzed using WebLogo. ${ }^{31}$ The overall frequencies of 19 amino acids (except cysteine) were counted using the ExPASy ProtParam tool.

\section{Phage selection against streptavidin}

Phage of the sub-libraries XD9 to XD14 were produced by inoculating $500 \mathrm{ml}$ of

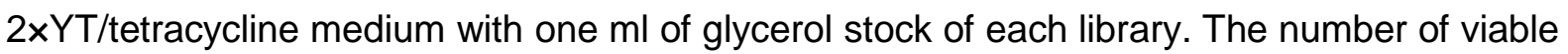
cells in the glycerol stocks was determined immediately after inoculation by plating 10-fold dilutions on tetracycline plates. The cultures were incubated at $30^{\circ} \mathrm{C}$ at $200 \mathrm{rpm}$ for $16 \mathrm{hrs}$. Phage of each one of the six libraries were purified by PEG-precipitation as described previously. ${ }^{15}$ During phage production, the cysteines of phage-displayed peptides were oxidized to form bicyclic peptides. Phage from different libraries were pooled and blocked in buffer W1 (10 mM Tris-Cl, pH 7.4, $150 \mathrm{mM} \mathrm{NaCl}, 10 \mathrm{mM} \mathrm{MgCl} 2,1 \mathrm{mM} \mathrm{CaCl}$ ) containing 1\% of BSA for $30 \mathrm{~min}$. The streptavidin magnetic beads (Dynabeads M-280, Thermo Fisher) were also blocked in the same buffer for $30 \mathrm{~min}$. Ten microliters of magnetic beads 
containing around $30 \mathrm{pmol}$ of streptavidin $(3 \mathrm{pmol} / \mu \mathrm{l})$ were incubated with the phage peptide library at room temperature overnight. After washing eight times with buffer W1 containing $0.1 \%$ Tween-20 and twice with $\mathrm{W} 1$, the magnetic beads were mixed with exponentially growing E. coli TG1 cells for infection ( $60 \mathrm{~min}$ at $37^{\circ} \mathrm{C}$ ). The infected $E$. coli TG1 cells were plated on a large (14 cm diameter) $2 \times Y T /$ tetracycline agar plate and incubated at $37^{\circ} \mathrm{C}$ overnight. The cells on the plate were stored as glycerol stock and were used to produce phage for a second round of selection. In the second round of phage selection, phage were produced in a culture volume of $25 \mathrm{ml}$, purified, and subjected to an affinity selection as in the first round. Peptides isolated in the second round were identified by NGS as described above.

\section{Synthesis of peptides}

Peptides were synthesized in-house by standard solid-phase peptide synthesis using Fmocprotected amino acids (scale, $0.03 \mathrm{mmol}$ ). As a solid support, Rink amide AM resin was used to obtain peptides with a free $\mathrm{N}$-terminus and an amidated $\mathrm{C}$-terminus. For labeling of peptides with fluorescein, 5(6)-carboxyfluorescein (Sigma-Aldrich) was coupled to the $\mathrm{N}$ terminus of the peptide during solid-phase peptide synthesis. Three equivalents $(0.09 \mathrm{mmol})$ of 5(6)-carboxyfluorescein, HATU, and DIPEA, each in $0.5 \mathrm{ml}$ dimethylformamide (DMF), were added to the resin and incubated for $2 \mathrm{hrs}$ at $400 \mathrm{rpm}$ at room temperature. The resin was washed four times with DMF, and the fluorescence-labeled peptides were cleaved from the resin with a cleavage cocktail of $90 \%$ trifluoroacetic acid (TFA), $2.5 \% \mathrm{H}_{2} \mathrm{O}, 2.5 \%$ thioanisol, $2.5 \%$ phenol, and 2.5\% 1.2-ethanedithiol and were partially purified by cold ether precipitation. Crude peptide was dissolved in $70 \%$ aqueous buffer $\left(60 \mathrm{mM} \mathrm{NH}_{4} \mathrm{HCO}_{3}, \mathrm{pH}\right.$ 8.0 ), $20 \%$ acetonitrile, and $10 \%$ DMSO at room temperature overnight for oxidation. The product was purified by reversed-phase chromatography on a preparative $\mathrm{C} 18$ column, and $\mathrm{H}_{2} \mathrm{O}(0.1 \%$ TFA $)$ and acetonitrile (0.1\% TFA) were used as solvents. Fractions of three isomers of bicyclic peptides were lyophilized and dissolved in DMSO. The purity was determined by analytical RP-HPLC (Agilent 1260 HPLC system, Agilent) using an analytical C18 column. The identity was confirmed by LC-MS (LCMS2020, Shimadzu).

\section{Determination of binding affinity by fluorescence polarization}

Binding studies were performed using $25 \mathrm{nM}$ of fluorescent peptide incubated with increasing streptavidin (Abcam) concentrations in PBS (pH 7.4, 0.01\% Tween-20). Peptide 
protein mixtures $(60 \mu \mathrm{l})$ were transferred to a Greiner 386-well black-bottom plate and fluorescence polarization in each well was measured after 20 min incubation using a multiwell plate reader (Infinite-200PRO, TECAN). Dissociation constants $\left(K_{\mathrm{D}}\right)$ of fluoresceinlabeled peptides were determined by non-linear regression analyses of fluorescence anisotropy $(A)$ versus total concentration of streptavidin monomer $[P]_{T}$ using Equation 1.

$$
A=A_{f}+\left(A_{b}-A_{f}\right) \times\left\{\frac{[L]_{T}+K_{D}+[P]_{T}-\sqrt{\left([L]_{T}+K_{D}+[P]_{T}\right)^{2}-4[L]_{T}[P]_{T}}}{2[L]_{T}}\right\}
$$

GraphPad Prism 5 software was used for the analysis, with the fluorescence anisotropy of the free peptide $\left(A_{f}\right)$, the fully bound peptide $\left(A_{b}\right)$, and the total concentration of fluorescent ligand $[L]_{T}=25 \mathrm{nM}$. 


\section{SUPPLEMENTARY TABLES}

Table S1. Sequences of degenerated DNA primers used for the whole-plasmid PCR.

\begin{tabular}{|c|c|c|}
\hline Sub-library & Primer name & Primer sequence ( $5^{\prime}$ to $\left.3^{\prime}\right)$ \\
\hline \multirow{10}{*}{ XD9 } & XD9_1 & TGCGGCCCAGCCGGCCATGGCGNNKTGTTGTTGTNNKNNKNNKTGTNNKGGTTCTGGCGCTGAAACTGTTGAAAGTTG \\
\hline & XD9_2 & TGCGGCCCAGCCGGCCATGGCGNNKTGTTGTNNKTGTNNKNNKTGTNNKGGTTCTGGCGCTGAAACTGTTGAAAGTTG \\
\hline & XD9_3 & TGCGGCCCAGCCGGCCATGGCGNNKTGTTGTNNKNNKTGTNNKTGTNNKGGTTCTGGCGCTGAAACTGTTGAAAGTTG \\
\hline & XD9_4 & TGCGGCCCAGCCGGCCATGGCGNNKTGTTGTNNKNNKNNKTGTTGTNNKGGTTCTGGCGCTGAAACTGTTGAAAGTTG \\
\hline & XD9_5 & TGCGGCCCAGCCGGCCATGGCGNNKTGTNNKTGTTGTNNKNNKTGTNNKGGTTCTGGCGCTGAAACTGTTGAAAGTTG \\
\hline & XD9_6 & TGCGGCCCAGCCGGCCATGGCGNNKTGTNNKTGTNNKTGTNNKTGTNNKGGTTCTGGCGCTGAAACTGTTGAAAGTTG \\
\hline & XD9_7 & TGCGGCCCAGCCGGCCATGGCGNNKTGTNNKTGTNNKNNKTGTTGTNNKGGTTCTGGCGCTGAAACTGTTGAAAGTTG \\
\hline & XD9_8 & TGCGGCCCAGCCGGCCATGGCGNNKTGTNNKNNKTGTTGTNNKTGTNNKGGTTCTGGCGCTGAAACTGTTGAAAGTTG \\
\hline & XD9_9 & TGCGGCCCAGCCGGCCATGGCGNNKTGTNNKNNKTGTNNKTGTTGTNNKGGTTCTGGCGCTGAAACTGTTGAAAGTTG \\
\hline & XD9_10 & TGCGGCCCAGCCGGCCATGGCGNNKTGTNNKNNKNNKTGTTGTTGTNNKGGTTCTGGCGCTGAAACTGTTGAAAGTTG \\
\hline \multirow[t]{15}{*}{ XD10 } & XD10_1 & TGCGGCCCAGCCGGCCATGGCGNNKTGTTGTTGTNNKNNKNNKNNKTGTNNKGGTTCTGGCGCTGAAACTGTTGAAAGTTG \\
\hline & XD10_2 & TGCGGCCCAGCCGGCCATGGCGNNKTGTTGTNNKTGTNNKNNKNNKTGTNNKGGTTCTGGCGCTGAAACTGTTGAAAGTTG \\
\hline & XD10_3 & TGCGGCCCAGCCGGCCATGGCGNNKTGTTGTNNKNNKTGTNNKNNKTGTNNKGGTTCTGGCGCTGAAACTGTTGAAAGTTG \\
\hline & XD10_4 & TGCGGCCCAGCCGGCCATGGCGNNKTGTTGTNNKNNKNNKTGTNNKTGTNNKGGTTCTGGCGCTGAAACTGTTGAAAGTTG \\
\hline & XD10_5 & TGCGGCCCAGCCGGCCATGGCGNNKTGTTGTNNKNNKNNKNNKTGTTGTNNKGGTTCTGGCGCTGAAACTGTTGAAAGTTG \\
\hline & XD10_6 & TGCGGCCCAGCCGGCCATGGCGNNKTGTNNKTGTTGTNNKNNKNNKTGTNNKGGTTCTGGCGCTGAAACTGTTGAAAGTTG \\
\hline & XD10_7 & TGCGGCCCAGCCGGCCATGGCGNNKTGTNNKTGTNNKTGTNNKNNKTGTNNKGGTTCTGGCGCTGAAACTGTTGAAAGTTG \\
\hline & XD10_8 & TGCGGCCCAGCCGGCCATGGCGNNKTGTNNKTGTNNKNNKTGTNNKTGTNNKGGTTCTGGCGCTGAAACTGTTGAAAGTTG \\
\hline & XD10_9 & TGCGGCCCAGCCGGCCATGGCGNNKTGTNNKTGTNNKNNKNNKTGTTGTNNKGGTTCTGGCGCTGAAACTGTTGAAAGTTG \\
\hline & XD10_10 & TGCGGCCCAGCCGGCCATGGCGNNKTGTNNKNNKTGTTGTNNKNNKTGTNNKGGTTCTGGCGCTGAAACTGTTGAAAGTTG \\
\hline & XD10_11 & TGCGGCCCAGCCGGCCATGGCGNNKTGTNNKNNKTGTNNKTGTNNKTGTNNKGGTTCTGGCGCTGAAACTGTTGAAAGTTG \\
\hline & XD10_12 & TGCGGCCCAGCCGGCCATGGCGNNKTGTNNKNNKTGTNNKNNKTGTTGTNNKGGTTCTGGCGCTGAAACTGTTGAAAGTTG \\
\hline & XD10_13 & TGCGGCCCAGCCGGCCATGGCGNNKTGTNNKNNKNNKTGTTGTNNKTGTNNKGGTTCTGGCGCTGAAACTGTTGAAAGTTG \\
\hline & XD10_14 & TGCGGCCCAGCCGGCCATGGCGNNKTGTNNKNNKNNKTGTNNKTGTTGTNNKGGTTCTGGCGCTGAAACTGTTGAAAGTTG \\
\hline & XD10_15 & TGCGGCCCAGCCGGCCATGGCGNNKTGTNNKNNKNNKNNKTGTTGTTGTNNKGGTTCTGGCGCTGAAACTGTTGAAAGTTG \\
\hline \multirow[t]{18}{*}{ XD11 } & XD11_1 & TGCGGCCCAGCCGGCCATGGCGNNKTGTTGTTGTNNKNNKNNKNNKNNKTGTNNKGGTTCTGGCGCTGAAACTGTTGAAAGTTG \\
\hline & XD11_2 & TGCGGCCCAGCCGGCCATGGCGNNKTGTTGTNNKTGTNNKNNKNNKNNKTGTNNKGGTTCTGGCGCTGAAACTGTTGAAAGTTG \\
\hline & XD11_3 & TGCGGCCCAGCCGGCCATGGCGNNKTGTTGTNNKNNKTGTNNKNNKNNKTGTNNKGGTTCTGGCGCTGAAACTGTTGAAAGTTG \\
\hline & XD11_4 & TGCGGCCCAGCCGGCCATGGCGNNKTGTTGTNNKNNKNNKTGTNNKNNKTGTNNKGGTTCTGGCGCTGAAACTGTTGAAAGTTG \\
\hline & XD11_5 & TGCGGCCCAGCCGGCCATGGCGNNKTGTTGTNNKNNKNNKNNKTGTNNKTGTNNKGGTTCTGGCGCTGAAACTGTTGAAAGTTG \\
\hline & XD11_6 & TGCGGCCCAGCCGGCCATGGCGNNKTGTTGTNNKNNKNNKNNKNNKTGTTGTNNKGGTTCTGGCGCTGAAACTGTTGAAAGTTG \\
\hline & XD11_7 & TGCGGCCCAGCCGGCCATGGCGNNKTGTNNKTGTTGTNNKNNKNNKNNKTGTNNKGGTTCTGGCGCTGAAACTGTTGAAAGTTG \\
\hline & XD11_8 & TGCGGCCCAGCCGGCCATGGCGNNKTGTNNKTGTNNKTGTNNKNNKNNKTGTNNKGGTTCTGGCGCTGAAACTGTTGAAAGTTG \\
\hline & XD11_9 & TGCGGCCCAGCCGGCCATGGCGNNKTGTNNKTGTNNKNNKTGTNNKNNKTGTNNKGGTTCTGGCGCTGAAACTGTTGAAAGTTG \\
\hline & XD11_10 & TGCGGCCCAGCCGGCCATGGCGNNKTGTNNKTGTNNKNNKNNKTGTNNKTGTNNKGGTTCTGGCGCTGAAACTGTTGAAAGTTG \\
\hline & XD11_11 & TGCGGCCCAGCCGGCCATGGCGNNKTGTNNKTGTNNKNNKNNKNNKTGTTGTNNKGGTTCTGGCGCTGAAACTGTTGAAAGTTG \\
\hline & XD11_12 & TGCGGCCCAGCCGGCCATGGCGNNKTGTNNKNNKTGTTGTNNKNNKNNKTGTNNKGGTTCTGGCGCTGAAACTGTTGAAAGTTG \\
\hline & XD11_13 & TGCGGCCCAGCCGGCCATGGCGNNKTGTNNKNNKTGTNNKTGTNNKNNKTGTNNKGGTTCTGGCGCTGAAACTGTTGAAAGTTG \\
\hline & XD11_14 & TGCGGCCCAGCCGGCCATGGCGNNKTGTNNKNNKTGTNNKNNKTGTNNKTGTNNKGGTTCTGGCGCTGAAACTGTTGAAAGTTG \\
\hline & XD11_15 & TGCGGCCCAGCCGGCCATGGCGNNKTGTNNKNNKTGTNNKNNKNNKTGTTGTNNKGGTTCTGGCGCTGAAACTGTTGAAAGTTG \\
\hline & XD11_16 & TGCGGCCCAGCCGGCCATGGCGNNKTGTNNKNNKNNKTGTTGTNNKNNKTGTNNKGGTTCTGGCGCTGAAACTGTTGAAAGTTG \\
\hline & XD11_17 & TGCGGCCCAGCCGGCCATGGCGNNKTGTNNKNNKNNKTGTNNKTGTNNKTGTNNKGGTTCTGGCGCTGAAACTGTTGAAAGTTG \\
\hline & XD11_18 & TGCGGCCCAGCCGGCCATGGCGNNKTGTNNKNNKNNKTGTNNKNNKTGTTGTNNKGGTTCTGGCGCTGAAACTGTTGAAAGTTG \\
\hline
\end{tabular}




\begin{tabular}{|c|c|c|}
\hline & XD11_19 & TGCGGCCCAGCCGGCCATGGCGNNKTGTNNKNNKNNKNNKTGTTGTNNKTGTNNKGGTTCTGGCGCTGAAACTGTTGAAAGTTG \\
\hline & XD11_20 & TGCGGCCCAGCCGGCCATGGCGNNKTGTNNKNNKNNKNNKTGTNNKTGTTGTNNKGGTTCTGGCGCTGAAACTGTTGAAAGTTG \\
\hline & XD11_21 & TGCGGCCCAGCCGGCCATGGCGNNKTGTNNKNNKNNKNNKNNKTGTTGTTGTNNKGGTTCTGGCGCTGAAACTGTTGAAAGTTG \\
\hline \multirow[t]{28}{*}{ XD12 } & XD12_1 & TGCGGCCCAGCCGGCCATGGCGNNKTGTTGTTGTNNKNNKNNKNNKNNKNNKTGTNNKGGTTCTGGCGCTGAAACTGTTGAAAGTTG \\
\hline & XD12_2 & TGCGGCCCAGCCGGCCATGGCGNNKTGTTGTNNKTGTNNKNNKNNKNNKNNKTGTNNKGGTTCTGGCGCTGAAACTGTTGAAAGTTG \\
\hline & XD12_3 & TGCGGCCCAGCCGGCCATGGCGNNKTGTTGTNNKNNKTGTNNKNNKNNKNNKTGTNNKGGTTCTGGCGCTGAAACTGTTGAAAGTTG \\
\hline & XD12_4 & TGCGGCCCAGCCGGCCATGGCGNNKTGTTGTNNKNNKNNKTGTNNKNNKNNKTGTNNKGGTTCTGGCGCTGAAACTGTTGAAAGTTG \\
\hline & XD12_5 & TGCGGCCCAGCCGGCCATGGCGNNKTGTTGTNNKNNKNNKNNKTGTNNKNNKTGTNNKGGTTCTGGCGCTGAAACTGTTGAAAGTTG \\
\hline & XD12_6 & TGCGGCCCAGCCGGCCATGGCGNNKTGTTGTNNKNNKNNKNNKNNKTGTNNKTGTNNKGGTTCTGGCGCTGAAACTGTTGAAAGTTG \\
\hline & XD12_7 & TGCGGCCCAGCCGGCCATGGCGNNKTGTTGTNNKNNKNNKNNKNNKNNKTGTTGTNNKGGTTCTGGCGCTGAAACTGTTGAAAGTTG \\
\hline & XD12_8 & TGCGGCCCAGCCGGCCATGGCGNNKTGTNNKTGTTGTNNKNNKNNKNNKNNKTGTNNKGGTTCTGGCGCTGAAACTGTTGAAAGTTG \\
\hline & XD12_9 & TGCGGCCCAGCCGGCCATGGCGNNKTGTNNKTGTNNKTGTNNKNNKNNKNNKTGTNNKGGTTCTGGCGCTGAAACTGTTGAAAGTTG \\
\hline & XD12_10 & TGCGGCCCAGCCGGCCATGGCGNNKTGTNNKTGTNNKNNKTGTNNKNNKNNKTGTNNKGGTTCTGGCGCTGAAACTGTTGAAAGTTG \\
\hline & XD12_11 & TGCGGCCCAGCCGGCCATGGCGNNKTGTNNKTGTNNKNNKNNKTGTNNKNNKTGTNNKGGTTCTGGCGCTGAAACTGTTGAAAGTTG \\
\hline & XD12_12 & TGCGGCCCAGCCGGCCATGGCGNNKTGTNNKTGTNNKNNKNNKNNKTGTNNKTGTNNKGGTTCTGGCGCTGAAACTGTTGAAAGTTG \\
\hline & XD12_13 & TGCGGCCCAGCCGGCCATGGCGNNKTGTNNKTGTNNKNNKNNKNNKNNKTGTTGTNNKGGTTCTGGCGCTGAAACTGTTGAAAGTTG \\
\hline & XD12_14 & TGCGGCCCAGCCGGCCATGGCGNNKTGTNNKNNKTGTTGTNNKNNKNNKNNKTGTNNKGGTTCTGGCGCTGAAACTGTTGAAAGTTG \\
\hline & XD12_15 & TGCGGCCCAGCCGGCCATGGCGNNKTGTNNKNNKTGTNNKTGTNNKNNKNNKTGTNNKGGTTCTGGCGCTGAAACTGTTGAAAGTTG \\
\hline & XD12_16 & TGCGGCCCAGCCGGCCATGGCGNNKTGTNNKNNKTGTNNKNNKTGTNNKNNKTGTNNKGGTTCTGGCGCTGAAACTGTTGAAAGTTG \\
\hline & XD12_17 & TGCGGCCCAGCCGGCCATGGCGNNKTGTNNKNNKTGTNNKNNKNNKTGTNNKTGTNNKGGTTCTGGCGCTGAAACTGTTGAAAGTTG \\
\hline & XD12_18 & TGCGGCCCAGCCGGCCATGGCGNNKTGTNNKNNKTGTNNKNNKNNKNNKTGTTGTNNKGGTTCTGGCGCTGAAACTGTTGAAAGTTG \\
\hline & XD12_19 & TGCGGCCCAGCCGGCCATGGCGNNKTGTNNKNNKNNKTGTTGTNNKNNKNNKTGTNNKGGTTCTGGCGCTGAAACTGTTGAAAGTTG \\
\hline & XD12_20 & TGCGGCCCAGCCGGCCATGGCGNNKTGTNNKNNKNNKTGTNNKTGTNNKNNKTGTNNKGGTTCTGGCGCTGAAACTGTTGAAAGTTG \\
\hline & XD12_21 & TGCGGCCCAGCCGGCCATGGCGNNKTGTNNKNNKNNKTGTNNKNNKTGTNNKTGTNNKGGTTCTGGCGCTGAAACTGTTGAAAGTTG \\
\hline & XD12_22 & TGCGGCCCAGCCGGCCATGGCGNNKTGTNNKNNKNNKTGTNNKNNKNNKTGTTGTNNKGGTTCTGGCGCTGAAACTGTTGAAAGTTG \\
\hline & XD12_23 & TGCGGCCCAGCCGGCCATGGCGNNKTGTNNKNNKNNKNNKTGTTGTNNKNNKTGTNNKGGTTCTGGCGCTGAAACTGTTGAAAGTTG \\
\hline & XD12_24 & TGCGGCCCAGCCGGCCATGGCGNNKTGTNNKNNKNNKNNKTGTNNKTGTNNKTGTNNKGGTTCTGGCGCTGAAACTGTTGAAAGTTG \\
\hline & XD12_25 & TGCGGCCCAGCCGGCCATGGCGNNKTGTNNKNNKNNKNNKTGTNNKNNKTGTTGTNNKGGTTCTGGCGCTGAAACTGTTGAAAGTTG \\
\hline & XD12_26 & TGCGGCCCAGCCGGCCATGGCGNNKTGTNNKNNKNNKNNKNNKTGTTGTNNKTGTNNKGGTTCTGGCGCTGAAACTGTTGAAAGTTG \\
\hline & XD12_27 & TGCGGCCCAGCCGGCCATGGCGNNKTGTNNKNNKNNKNNKNNKTGTNNKTGTTGTNNKGGTTCTGGCGCTGAAACTGTTGAAAGTTG \\
\hline & XD12_28 & TGCGGCCCAGCCGGCCATGGCGNNKTGTNNKNNKNNKNNKNNKNNKTGTTGTTGTNNKGGTTCTGGCGCTGAAACTGTTGAAAGTTG \\
\hline \multirow[t]{18}{*}{ XD13 } & XD13_1 & TGCGGCCCAGCCGGCCATGGCGNNKTGTTGTTGTNNKNNKNNKNNKNNKNNKNNKTGTNNKGGTTCTGGCGCTGAAACTGTTGAAAGTTG \\
\hline & XD13_2 & TGCGGCCCAGCCGGCCATGGCGNNKTGTTGTNNKTGTNNKNNKKNNKNNKNNKNNKTGTNNKGGTTCTGGCGCTGAAACTGTTGAAAGTTG \\
\hline & XD13_3 & TGCGGCCCAGCCGGCCATGGCGNNKTGTTGTNNKNNKTGTNNKNNKNNKNNKNNKTGTNNKGGTTCTGGCGCTGAAACTGTTGAAAGTTG \\
\hline & XD13_4 & TGCGGCCCAGCCGGCCATGGCGNNKTGTTGTNNKNNKNNKTTGTNNKNNKNNKNNKTGTNNKGGTTCTGGCGCTGAAACTGTTGAAAGTTG \\
\hline & XD13_5 & TGCGGCCCAGCCGGCCATGGCGNNKTGTTGTNNKNNKNNKNNKTGTNNKNNKNNKTGTNNKGGTTCTGGCGCTGAAACTGTTGAAAGTTG \\
\hline & XD13_6 & TGCGGCCCAGCCGGCCATGGCGNNKTGTTGTNNKNNKNNKNNKNNKTGTNNKNNKTGTNNKGGTTCTGGCGCTGAAACTGTTGAAAGTTG \\
\hline & XD13_7 & TGCGGCCCAGCCGGCCATGGCGNNKTGTTGTNNKNNKNNKNNKNNKNNKTGTNNKTGTNNKGGTTCTGGCGCTGAAACTGTTGAAAGTTG \\
\hline & XD13_8 & TGCGGCCCAGCCGGCCATGGCGNNKTGTTGTNNKNNKNNKNNKNNKNNKNNKTGTTGTNNKGGTTCTGGCGCTGAAACTGTTGAAAGTTG \\
\hline & XD13_9 & TGCGGCCCAGCCGGCCATGGCGNNKTGTNNKTGTTGTNNKNNKNNNKNNKNNKNNKTGTNNKGGTTCTGGCGCTGAAACTGTTGAAAGTTG \\
\hline & XD13_10 & TGCGGCCCAGCCGGCCATGGCGNNKTGTNNKTGTNNKTGTNNKNNKNNKNNKNNKTGTNNKGGTTCTGGCGCTGAAACTGTTGAAAGTTG \\
\hline & XD13_11 & TGCGGCCCAGCCGGCCATGGCGNNKTGTNNKTGTNNKNNKTGTNNKNNKNNKNNKTGTNNKGGTTCTGGCGCTGAAACTGTTGAAAGTTG \\
\hline & XD13_12 & TGCGGCCCAGCCGGCCATGGCGNNKTGTNNKTGTNNKNNKNNKTGTNNKNNKNNKTGTNNKGGTTCTGGCGCTGAAACTGTTGAAAGTTG \\
\hline & XD13_13 & TGCGGCCCAGCCGGCCATGGCGNNKTGTNNKTGTNNKNNKNNKNNKTGTNNKNNKTGTNNKGGTTCTGGCGCTGAAACTGTTGAAAGTTG \\
\hline & XD13_14 & TGCGGCCCAGCCGGCCATGGCGNNKTGTNNKTGTNNKNNKNNKNNKNNKTGTNNKTGTNNKGGTTCTGGCGCTGAAACTGTTGAAAGTTG \\
\hline & XD13_15 & TGCGGCCCAGCCGGCCATGGCGNNKTGTNNKTGTNNKNNKNNKNNKNNKNNKTGTTGTNNKGGTTCTGGCGCTGAAACTGTTGAAAGTTG \\
\hline & XD13_16 & TGCGGCCCAGCCGGCCATGGCGNNKTGTNNKNNKTGTTGTNNKNNKNNKNNKNNKTGTNNKGGTTCTGGCGCTGAAACTGTTGAAAGTTG \\
\hline & XD13_17 & TGCGGCCCAGCCGGCCATGGCGNNKTGTNNKNNKTGTNNKTGTNNKNNKNNKNNKTGTNNKGGTTCTGGCGCTGAAACTGTTGAAAGTTG \\
\hline & XD13_18 & TGCGGCCCAGCCGGCCATGGCGNNKTGTNNKNNKTGTNNKNNKTGTNNKNNKNNKTGTNNKGGTTCTGGCGCTGAAACTGTTGAAAGTTG \\
\hline
\end{tabular}




\begin{tabular}{|c|c|c|}
\hline & XD13_19 & TGCGGCCCAGCCGGCCATGGCGNNKTGTNNKNNKTGTNNKNNKNNKTGTNNKNNKTGTNNKGGTTCTGGCGCTGAAACTGTTGAAAGTTG \\
\hline & XD13_20 & TGCGGCCCAGCCGGCCATGGCGNNKTGTNNKNNKTGTNNKNNKNNKNNKTGTNNKTGTNNKGGTTCTGGCGCTGAAACTGTTGAAAGTTG \\
\hline & XD13_21 & TGCGGCCCAGCCGGCCATGGCGNNKTGTNNKNNKTGTNNKNNKNNKNNKNNKTGTTGTNNKGGTTCTGGCGCTGAAACTGTTGAAAGTTG \\
\hline & XD13_22 & TGCGGCCCAGCCGGCCATGGCGNNKTGTNNKNNKNNKTGTTGTNNKNNKNNKNNKTGTNNKGGTTCTGGCGCTGAAACTGTTGAAAGTTG \\
\hline & XD13_23 & TGCGGCCCAGCCGGCCATGGCGNNKTGTNNKNNKNNKTGTNNKTGTNNKNNKNNKTGTNNKGGTTCTGGCGCTGAAACTGTTGAAAGTTG \\
\hline & XD13_24 & TGCGGCCCAGCCGGCCATGGCGNNKTGTNNKNNKNNKTGTNNKNNKTGTNNKNNKTGTNNKGGTTCTGGCGCTGAAACTGTTGAAAGTTG \\
\hline & XD13_25 & TGCGGCCCAGCCGGCCATGGCGNNKTGTNNKNNKNNKTGTNNKNNKNNKTGTNNKTGTNNKGGTTCTGGCGCTGAAACTGTTGAAAGTTG \\
\hline & XD13_26 & TGCGGCCCAGCCGGCCATGGCGNNKTGTNNKNNKNNKTGTNNKNNKNNKNNKTGTTGTNNKGGTTCTGGCGCTGAAACTGTTGAAAGTTG \\
\hline & XD13_27 & TGCGGCCCAGCCGGCCATGGCGNNKTGTNNKNNKNNKNNKTGTTGTNNKNNKNNKTGTNNKGGTTCTGGCGCTGAAACTGTTGAAAGTTG \\
\hline & XD13_28 & TGCGGCCCAGCCGGCCATGGCGNNKTGTNNKNNKNNKNNKTGTNNKTGTNNKNNKTGTNNKGGTTCTGGCGCTGAAACTGTTGAAAGTTG \\
\hline & XD13_29 & TGCGGCCCAGCCGGCCATGGCGNNKTGTNNKNNKNNKNNKTGTNNKNNKTGTNNKTGTNNKGGTTCTGGCGCTGAAACTGTTGAAAGTTG \\
\hline & XD13_30 & TGCGGCCCAGCCGGCCATGGCGNNKTGTNNKNNKNNKNNKTGTNNKNNKNNKTGTTGTNNKGGTTCTGGCGCTGAAACTGTTGAAAGTTG \\
\hline & XD13_31 & TGCGGCCCAGCCGGCCATGGCGNNKTGTNNKNNKNNKNNKNNNKTGTTGTNNKNNKTGTNNKGGTTCTGGCGCTGAAACTGTTGAAAGTTG \\
\hline & XD13_32 & TGCGGCCCAGCCGGCCATGGCGNNKTGTNNKNNKNNKNNKNNKKTGTNNKTGTNNKTGTNNKGGTTCTGGCGCTGAAACTGTTGAAAGTTG \\
\hline & XD13_33 & TGCGGCCCAGCCGGCCATGGCGNNKTGTNNKNNKNNKNNKNNKTGTNNKNNKTGTTGTNNKGGTTCTGGCGCTGAAACTGTTGAAAGTTG \\
\hline & XD13_34 & TGCGGCCCAGCCGGCCATGGCGNNKTGTNNKNNKNNKNNKNNKNNKTGTTGTNNKTGTNNKGGTTCTGGCGCTGAAACTGTTGAAAGTTG \\
\hline & XD13_35 & TGCGGCCCAGCCGGCCATGGCGNNKTGTNNKNNKNNKNNKNNKNNKTGTNNKTGTTGTNNKGGTTCTGGCGCTGAAACTGTTGAAAGTTG \\
\hline & XD13_36 & TGCGGCCCAGCCGGCCATGGCGNNKTGTNNKNNKNNKNNKNNKKNNKNNKTGTTGTTGTNNKGGTTCTGGCGCTGAAACTGTTGAAAGTTG \\
\hline \multirow[t]{31}{*}{ XD14 } & XD14_1 & TGCGGCCCAGCCGGCCATGGCGNNKTGTTGTTGTNNKNNKNNKNNKNNKNNKNNKNNKTGTNNKGGTTCTGGCGCTGAAACTGTTGAAAGTTG \\
\hline & XD14_2 & TGCGGCCCAGCCGGCCATGGCGNNKTGTTGTNNKTGTNNKNNKNNKNNKNNKNNKNNKTGTNNKGGTTCTGGCGCTGAAACTGTTGAAAGTTG \\
\hline & XD14_3 & TGCGGCCCAGCCGGCCATGGCGNNKTGTTGTNNKNNKTGTNNKNNKNNKNNKNNKNNKTGTNNKGGTTCTGGCGCTGAAACTGTTGAAAGTTG \\
\hline & XD14_4 & TGCGGCCCAGCCGGCCATGGCGNNKTGTTGTNNKNNKNNKTGTNNKNNKNNKNNKNNKTGTNNKGGTTCTGGCGCTGAAACTGTTGAAAGTTG \\
\hline & XD14_5 & TGCGGCCCAGCCGGCCATGGCGNNKTGTTGTNNKNNKNNKNNKTGTNNKNNKNNKNNKTGTNNKGGTTCTGGCGCTGAAACTGTTGAAAGTTG \\
\hline & XD14_6 & TGCGGCCCAGCCGGCCATGGCGNNKTGTTGTNNKNNKNNKNNKNNKTGTNNKNNKNNKTGTNNKGGTTCTGGCGCTGAAACTGTTGAAAGTTG \\
\hline & XD14_7 & TGCGGCCCAGCCGGCCATGGCGNNKTGTTGTNNKNNKNNKNNKNNKNNKTGTNNKNNKTGTNNKGGTTCTGGCGCTGAAACTGTTGAAAGTTG \\
\hline & XD14_8 & TGCGGCCCAGCCGGCCATGGCGNNKTGTTGTNNKNNKNNKNNKNNKNNKNNKTGTNNKTGTNNKGGTTCTGGCGCTGAAACTGTTGAAAGTTG \\
\hline & XD14_9 & TGCGGCCCAGCCGGCCATGGCGNNKTGTTGTNNKNNKNNKNNKNNKNNKNNKNNKTGTTGTNNKGGTTCTGGCGCTGAAACTGTTGAAAGTTG \\
\hline & XD14_10 & TGCGGCCCAGCCGGCCATGGCGNNKTGTNNKTGTTGTNNKNNKNNKNNKNNKNNKNNKTGTNNKGGTTCTGGCGCTGAAACTGTTGAAAGTTG \\
\hline & XD14_11 & TGCGGCCCAGCCGGCCATGGCGNNKTGTNNKTGTNNKTGTNNKNNKNNKNNKNNKNNKTGTNNKGGTTCTGGCGCTGAAACTGTTGAAAGTTG \\
\hline & XD14_12 & TGCGGCCCAGCCGGCCATGGCGNNKTGTNNKTGTNNKNNKTGTNNKNNKNNKNNKNNKTGTNNKGGTTCTGGCGCTGAAACTGTTGAAAGTTG \\
\hline & XD14_13 & TGCGGCCCAGCCGGCCATGGCGNNKTGTNNKTGTNNKNNKNNKTGTNNKNNKNNKNNKTGTNNKGGTTCTGGCGCTGAAACTGTTGAAAGTTG \\
\hline & XD14_14 & TGCGGCCCAGCCGGCCATGGCGNNKTGTNNKTGTNNKNNKNNKNNKTGTNNKNNKNNKTGTNNKGGTTCTGGCGCTGAAACTGTTGAAAGTTG \\
\hline & XD14_15 & TGCGGCCCAGCCGGCCATGGCGNNKTGTNNKTGTNNKNNKNNKNNKNNKTGTNNKNNKTGTNNKGGTTCTGGCGCTGAAACTGTTGAAAGTTG \\
\hline & XD14_16 & TGCGGCCCAGCCGGCCATGGCGNNKTGTNNKTGTNNKNNKNNKNNKNNKNNKTGTNNKTGTNNKGGTTCTGGCGCTGAAACTGTTGAAAGTTG \\
\hline & XD14_17 & TGCGGCCCAGCCGGCCATGGCGNNKTGTNNKTGTNNKNNKNNKNNKNNKNNKNNKTGTTGTNNKGGTTCTGGCGCTGAAACTGTTGAAAGTTG \\
\hline & XD14_18 & TGCGGCCCAGCCGGCCATGGCGNNKTGTNNKNNKTGTTGTNNKNNKNNKNNKNNKNNKTGTNNKGGTTCTGGCGCTGAAACTGTTGAAAGTTG \\
\hline & XD14_19 & TGCGGCCCAGCCGGCCATGGCGNNKTGTNNKNNKTGTNNKTGTNNKNNKNNKNNKNNKTGTNNKGGTTCTGGCGCTGAAACTGTTGAAAGTTG \\
\hline & XD14_20 & TGCGGCCCAGCCGGCCATGGCGNNKTGTNNKNNKTGTNNKNNKTGTNNKNNKNNKNNKTGTNNKGGTTCTGGCGCTGAAACTGTTGAAAGTTG \\
\hline & XD14_21 & TGCGGCCCAGCCGGCCATGGCGNNKTGTNNKNNKTGTNNKNNKNNKTGTNNKNNKNNKTGTNNKGGTTCTGGCGCTGAAACTGTTGAAAGTTG \\
\hline & XD14_22 & TGCGGCCCAGCCGGCCATGGCGNNKTGTNNKNNKTGTNNKNNKNNKNNKTGTNNKNNKTGTNNKGGTTCTGGCGCTGAAACTGTTGAAAGTTG \\
\hline & XD14_23 & TGCGGCCCAGCCGGCCATGGCGNNKTGTNNKNNKTGTNNKNNKNNKNNKNNKTGTNNKTGTNNKGGTTCTGGCGCTGAAACTGTTGAAAGTTG \\
\hline & XD14_24 & TGCGGCCCAGCCGGCCATGGCGNNKTGTNNKNNKTGTNNKNNKNNKNNKNNKNNKTGTTGTNNKGGTTCTGGCGCTGAAACTGTTGAAAGTTG \\
\hline & XD14_25 & TGCGGCCCAGCCGGCCATGGCGNNKTGTNNKNNKNNKTGTTGTNNKNNKNNKNNKNNKTGTNNKGGTTCTGGCGCTGAAACTGTTGAAAGTTG \\
\hline & XD14_26 & TGCGGCCCAGCCGGCCATGGCGNNKTGTNNKNNKNNKTGTNNKTGTNNKNNKNNKNNKTGTNNKGGTTCTGGCGCTGAAACTGTTGAAAGTTG \\
\hline & XD14_27 & TGCGGCCCAGCCGGCCATGGCGNNKTGTNNKNNKNNKTGTNNKNNKTGTNNKNNKNNKTGTNNKGGTTCTGGCGCTGAAACTGTTGAAAGTTG \\
\hline & XD14_28 & TGCGGCCCAGCCGGCCATGGCGNNKTGTNNKNNKNNKTGTNNKNNKNNKTGTNNKNNKTGTNNKGGTTCTGGCGCTGAAACTGTTGAAAGTTG \\
\hline & XD14_29 & TGCGGCCCAGCCGGCCATGGCGNNKTGTNNKNNKNNKTGTNNKNNKNNKNNKTGTNNKTGTNNKGGTTCTGGCGCTGAAACTGTTGAAAGTTG \\
\hline & XD14_30 & TGCGGCCCAGCCGGCCATGGCGNNKTGTNNKNNKNNKTGTNNKNNKNNKNNKNNKTGTTGTNNKGGTTCTGGCGCTGAAACTGTTGAAAGTTG \\
\hline & XD14_31 & TGCGGCCCAGCCGGCCATGGCGNNKTGTNNKNNKNNKNNKTGTTGTNNKNNKNNKNNKTGTNNKGGTTCTGGCGCTGAAACTGTTGAAAGTTG \\
\hline
\end{tabular}




\begin{tabular}{|l|l|l|}
\hline & XD14_32 & TGCGGCCCAGCCGGCCATGGCGNNKTGTNNKNNKNNKNNKTGTNNKTGTNNKNNKNNKTGTNNKGGTTCTGGCGCTGAAACTGTTGAAAGTTG \\
\hline & XD14_33 & TGCGGCCCAGCCGGCCATGGCGNNKTGTNNKNNKNNKNNKTGTNNKNNKTGTNNKNNKTGTNNKGGTTCTGGCGCTGAAACTGTTGAAAGTTG \\
\hline & XD14_34 & TGCGGCCCAGCCGGCCATGGCGNNKTGTNNKNNKNNKNNKTGTNNKNNKNNKTGTNNKTGTNNKGGTTCTGGCGCTGAAACTGTTGAAAGTTG \\
\hline & XD14_35 & TGCGGCCCAGCCGGCCATGGCGNNKTGTNNKNNKNNKNNKTGTNNKNNKNNKNNKTGTTGTNNKGGTTCTGGCGCTGAAACTGTTGAAAGTTG \\
\hline & XD14_36 & TGCGGCCCAGCCGGCCATGGCGNNKTGTNNKNNKNNKNNKNNKTGTTGTNNKNNKNNKTGTNNKGGTTCTGGCGCTGAAACTGTTGAAAGTTG \\
\hline & XD14_37 & TGCGGCCCAGCCGGCCATGGCGNNKTGTNNKNNKNNKNNKNNKTGTNNKTGTNNKNNKTGTNNKGGTTCTGGCGCTGAAACTGTTGAAAGTTG \\
\hline & XD14_38 & TGCGGCCCAGCCGGCCATGGCGNNKTGTNNKNNKNNKNNKNNKTGTNNKNNKTGTNNKTGTNNKGGTTCTGGCGCTGAAACTGTTGAAAGTTG \\
\hline & XD14_39 & TGCGGCCCAGCCGGCCATGGCGNNKTGTNNKNNKNNKNNKNNKTGTNNKNNKNNKTGTTGTNNKGGTTCTGGCGCTGAAACTGTTGAAAGTTG \\
\hline & XD14_40 & TGCGGCCCAGCCGGCCATGGCGNNKTGTNNKNNKNNKNNNKNNKNNKTGTTGTNNKNNKTGTNNKGGTTCTGGCGCTGAAACTGTTGAAAGTTG \\
\hline & XD14_41 & TGCGGCCCAGCCGGCCATGGCGNNKTGTNNKNNKNNKNNNNNKNNKTGTNNKTGTNNKTGTNNKGGTTCTGGCGCTGAAACTGTTGAAAGTTG \\
\hline & XD14_42 & TGCGGCCCAGCCGGCCATGGCGNNKTGTNNKNNKNNKNNNNNKNNKTGTNNKNNKTGTTGTNNKGGTTCTGGCGCTGAAACTGTTGAAAGTTG \\
\hline & XD14_43 & TGCGGCCCAGCCGGCCATGGCGNNKTGTNNKNNKNNKNNKNNKNNKNNKTGTTGTNNKTGTNNKGGTTCTGGCGCTGAAACTGTTGAAAGTTG \\
\hline & XD14_44 & TGCGGCCCAGCCGGCCATGGCGNNKTGTNNKNNKNNKNNKNNKNNKNNKTGTNNKTGTTGTNNKGGTTCTGGCGCTGAAACTGTTGAAAGTTG \\
\hline & XD14_45 & TGCGGCCCAGCCGGCCATGGCGNNKTGTNNKNNKNNKNNNKNNKNNKNNKNNKTGTTGTTGTNNKGGTTCTGGCGCTGAAACTGTTGAAAGTTG \\
\hline
\end{tabular}


Table S2. Whole-plasmid PCR. Reagents are shown in the order in which they were added to the reaction tube.

\begin{tabular}{|l|l|l|l|}
\hline Reagent & Stock concentration & Final concentration & Volume added \\
\hline Autoclaved MQ water & $/$ & $/$ & $34 \mu \mathrm{l}$ \\
\hline $5 \mathrm{x}$ HF buffer & $5 \mathrm{x}$ & $1 \mathrm{x}$ & $10 \mu \mathrm{l}$ \\
\hline Forward primer & $10 \mu \mathrm{M}$ & $200 \mathrm{nM}$ & $1 \mu \mathrm{l}$ \\
\hline Reverse primer & $10 \mu \mathrm{M}$ & $200 \mathrm{nM}$ & $1 \mu \mathrm{l}$ \\
\hline dNTP & $10 \mathrm{mM}$ each & $200 \mu \mathrm{M}$ each & $1 \mu \mathrm{l}$ \\
\hline Template & $40 \mathrm{ng} / \mu \mathrm{l}$ & $0.8 \mathrm{ng} / \mu \mathrm{l}$ & $1 \mu \mathrm{l}$ \\
\hline Phusion polymerase & $2 \mathrm{U} / \mu \mathrm{l}$ & $0.08 \mathrm{U} / \mu \mathrm{l}$ & $2 \mu \mathrm{l}$ \\
\hline
\end{tabular}


Table S3. Primers used for the second PCR in NGS

\begin{tabular}{|l|l|}
\hline Primer & Sequence \\
\hline NGS PCR2 Forward S508 & AATGATACGGCGACCACCGAGATCTACACCTAAGCCTTCGTCGGCAGCGTC \\
\hline NGS PCR2 Reverse N704 & CAAGCAGAAGACGGCATACGAGATGCTCAGGAGTCTCGTGGGCTCGG \\
\hline
\end{tabular}




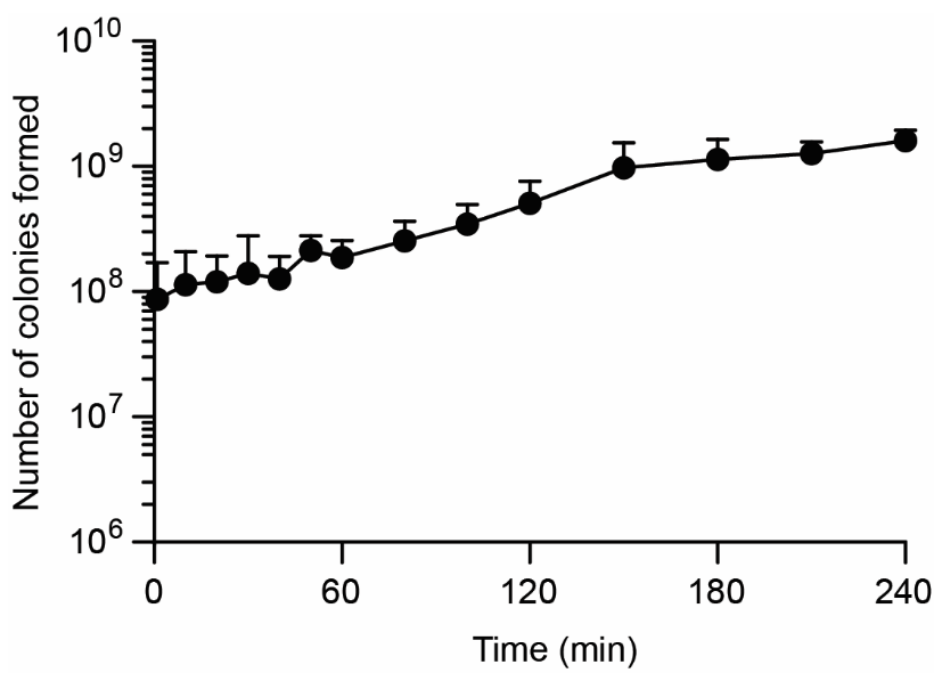

Figure S1. Influence of post-electroporation incubation time on number of colonies. Phage vector fd-tet-PK15 was electroporated into electrocompetent $E$. coli TG1 cells and incubated in recovery medium for 4 hours at $37^{\circ} \mathrm{C}$. Samples were taken at the indicated time points and the number of cells containing a vector determined by immediately plating dilutions and counting colonies. Mean values and standard deviations of three independent experiments are shown. 